\title{
THE CHILD OF THE DIABETIC WOMAN*
}

\author{
BY \\ JAMES W. FARQUHAR \\ From the Department of Child Life and Health, University of Edinburgh, and the Simpson Memorial Maternity Pavilion, \\ Royal Infirmary, Edinburgh
}

(RECEIVED FOR PUBLICATION JULY 28, 1958)

Over a century ago Bennewitz (1828), when delivering a diabetic woman, observed that the giant foetus whose head had been born but whose shoulders were stuck fast 'seemed anxious and sighed with a clear voice'. In this depressed state the infant died, as so many of his kind have done since.

Pregnancy complicating diabetes and the development of children born to diabetic women became problems only with the development of insulin. Before the dawn of the insulin era diabetes mellitus was associated with female infertility, possibly as a consequence of poor nutrition (Sinden and Longwell, 1949), and when pregnancy did occur the foetal mortality ranged from $40 \%$ (Duncan, 1883 ) to $70 \%$ (Eshner, 1907). With insulin, however, the infertile diabetic woman is now exceptional in the extensive experience of White (1952), and Stevenson (1956) found that in his Belfast series $70 \%$ were pregnant within one year of marriage and that over $90 \%$ were pregnant within two years. Although maternal mortality in diabetic pregnancy has been almost entirely eliminated, a distressing foetal loss persists. Until recently pre-viable abortions were included in the over-all foetal mortality figures. No evidence exists, however, to prove that abortions are any commoner among diabetic than among non-diabetic women (Peel and Oakley, 1950). A figure of $6.4 \%$ found by Pedowitz and Shlevin (1955) was well within the normal range in their experience, $10 \%$ of abortions were reported by Stevenson (1956), and Barns and Morgans (1949) discovered a diabetic abortion rate of $10.9 \%$ and a non-diabetic rate of $11 \cdot 8 \%$. Because of this only viable foetal loss rates are customarily compared.

The perinatal mortality for all booked pregnancies at the Simpson Memorial Maternity Pavilion has been less than 40 in 1,000 births in recent years, and this contrasts with the figure of 166 in 1,000 births

\footnotetext{
* A Honyman-Gillespie Post-graduate Lecture delivered at the University of Edinburgh on May 22, 1958.
}

for those diabetic women who were adequately supervised from not later than the twentieth week of gestation, and upon whom, or upon whose babies, exceptional and co-ordinated care was lavished by a team composed of an obstetrician, a physician and a paediatrician. These results are compared in Table 1 with other American and European series. The Danish and Belfast figures have been calculated for roughly the same years as this series but later improvement was noted in both. The neonatal death rate is given only where this could be calculated from the figures given.

The purpose of this paper is to describe the morphology of infants born to diabetic women, their clinical progress in the first month of life, their metabolic disorders, the possible links between maternal diabetes and the embryopathy, the management of the newly born and their further development up to the age of 10 years.

\section{Clinical Description and Progress of the Newborn.}

The children of diabetic men do not differ discernibly at birth from those born to non-diabetic men (Babbott, Rubin and Ginsburg, 1958). Those born to diabetic mothers, however, commonly exceed both the mean body weight and crown-heel length for their gestational age (Cardell, 1953; Pedersen, 1954). Because of their gigantism and because of a strong tendency toward intra-uterine death after the thirty-sixth week, caesarean birth some weeks before term is commonly practised, and most of the babies in this series were so delivered.

The infants are remarkable (Fig. 1) not only because, like foetal versions of Shadrach, Meshach and Abednego, they emerge at least alive from within the fiery metabolic furnace of diabetes mellitus, but because they resemble one another so closely that they might well be related. They are plump, sleek, liberally coated with vernix caseosa, full-faced and plethoric. The umbilical cord and the placenta share in the gigantism. During their first 


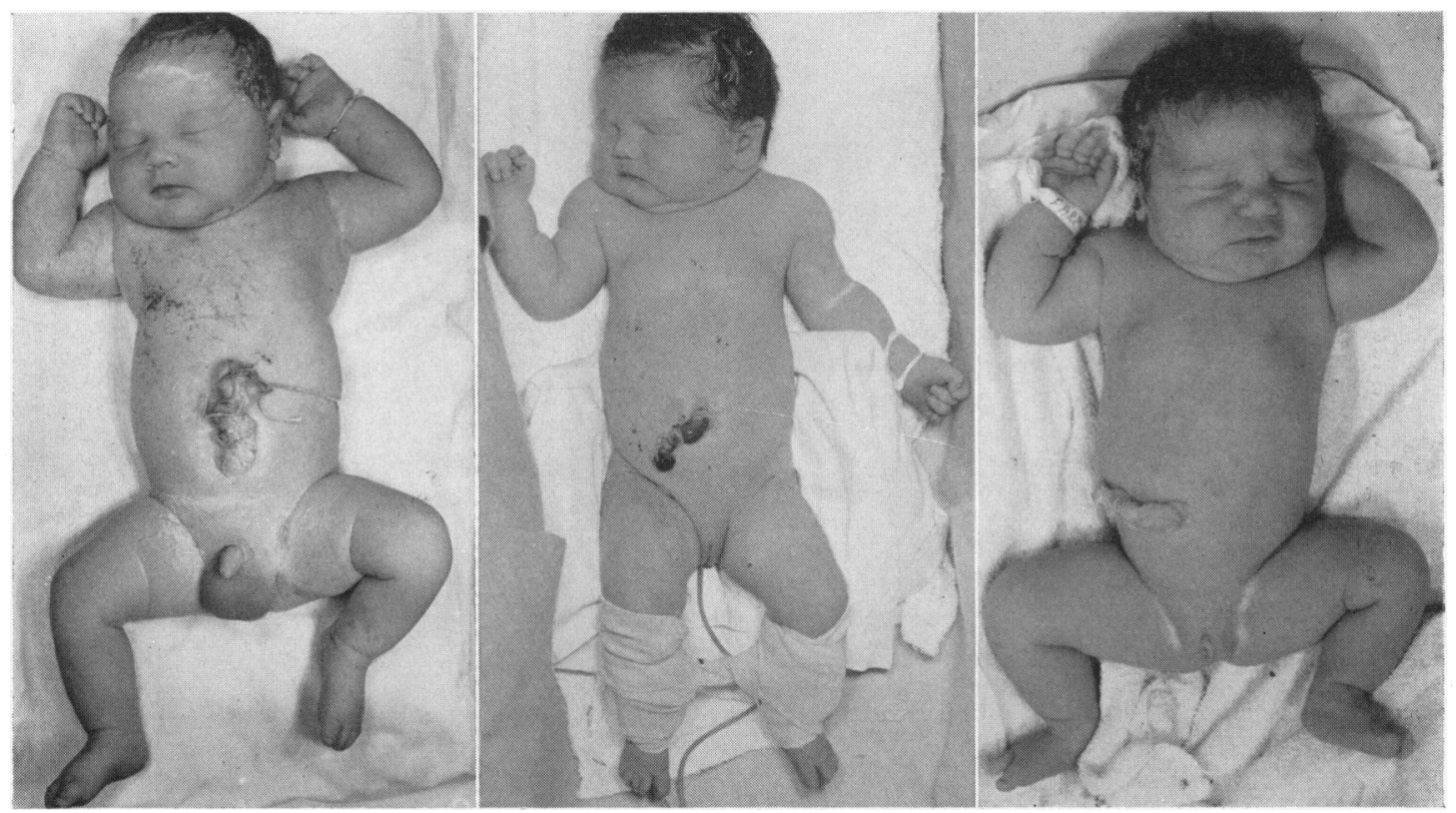

FIG. 1.-Unrelated infants of diabetic women.

'. . . for some of us are out of breath

And all of us are fat.' (Lewis Carroll.)

24 or more extra-uterine hours they lie on their backs, bloated and flushed, their legs flexed and abducted, their lightly closed hands on each side of the head, the abdomen prominent and their respiration sighing. They convey a distinct impression of having had such a surfeit of both food and fluid pressed upon them by an insistent hostess that they desire only peace so that they may recover from their excesses. And on the second day their resentment of the slightest noise improves the analogy while their trembling anxiety seems to speak of intra-uterine indiscretions of which we know nothing.

Of the 123 viable pregnancies in the series, occurring in women who were known to have diabetes mellitus, 96 resulted in the birth of a live child, and of these, $57(59.4 \%)$ survived the newborn period without serious incident. Most of them showed prolonged Moro embrace responses which were elicited so easily that even a light footfall in the room, a hand laid gently on the cot, or the movement of a camera shutter was sufficient to evoke a series of movements which have been described by the inexperienced as twitchings or convulsions.

Those infants whose first feed is delayed until the fourth day, for reasons which will be given later, will certainly become restless before then and will show some evidence of dehydration. Physiological jaundice is common and, as in infants of comparable gestational age, it may be quite deep and prolonged. Infection of the skin occurs easily unless strict precautions are taken. Very little breast tissue is apparent during the first two weeks.

Those babies whose clinical progress was abnormal may be grouped together as the 'dyspnoeic' and the 'cyanotic attack' infants. Loose as such descriptive terms may be, insufficient evidence exists as yet to support the adoption of others.

Dyspnoea (Fig. 2). Difficult respiration was observed in 21 babies $(21.9 \%)$. In some, respiration was established slowly, occasionally only with assistance, and breathing then remained distressed. In others the baby cried immediately on removal head first from the uterus, quickly became pink, and then after a few minutes or an hour or more dyspnoea gradually developed. In only two cases did respiratory difficulty make its first appearance after the first day, and one of these infants had pneumonia.

The duration of dyspnoea varied from a few hours to more than three days and is indicated in Fig. 2. Cyanosis of varying degree accompanied the forcible respirations, the sternal and costal indrawing and the strange tremulous expiratory whine which is known to the midwives as 'murmuring'. Seriously affected babies became very limp, and the Moro response, 


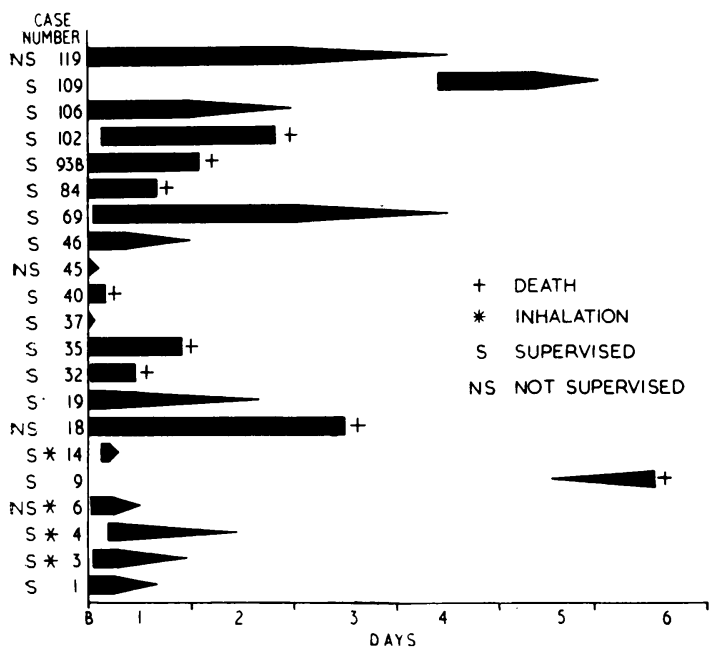

FIG. 2.-The duration of dyspnoea. Inhalation of glucose solution occurred in some cases. Supervision refers to ante-natal obstetric care.

so very active in the well offspring of the diabetic woman, was lost at least temporarily. All the deaths in this series were preceded by dyspnoea, and in all cases acute cyanotic attacks were superimposed upon the distress and were often the terminal event. The survivors showed gradual improvement over periods of up to 24 hours, and where dyspnoea became progressively less noticeable over six to nine hours the baby's recovery could be expected.

Cyanotic Attacks (Fig. 3). Cyanotic attacks were observed as unaccompanied abnormalities in 18 babies $(18.8 \%)$. Such incidents were unheralded and dramatic, and were characterized by infrequent or temporarily interrupted respiration and profound cyanosis. They were almost always already well established when observed by the nurse and unless the physician is spending much time simply observing premature babies, he may never see such an attack. The attacks were quite unlike that which is superimposed upon respiratory distress and more nearly resembled an exaggeration of the common irregular respiratory pattern of the small immature newborn infant (Boutourline-Young and Smith, 1950). It was as if the centre which inhibits respiration in pre-natal life (Barcroft, 1947) were temporarily to re-establish control. At one moment the infant was pink and well and then before the observer's eyes the pink skin gave way to grey and then to deepening shades of cyanosis. Respiration might be infrequent or even absent for a minute or longer. The infant became toneless and, in severe cases, apparently lifeless. Bradycardia was profound and was often found as soon as cyanosis

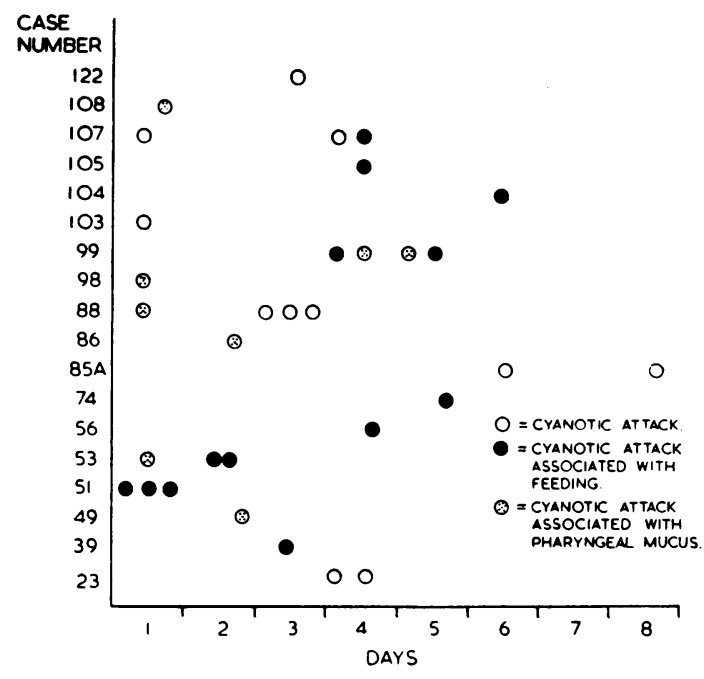

FIG. 3.-The time incidence of cyanotic attacks.

was obvious. It was, however, not necessarily the result of the same central discharge which arrested respiration, because hypopnoea or apnoea always existed for an undetermined space of time before the changing colour attracted the observer's attention.

Such attacks may occur at any time in the first week, they may be single or multiple and they are usually brief (Fig. 3). Some are associated with small accumulations of mucus which can be aspirated from the pharynx and others occur when premature attempts are made to feed the baby. Most of them cannot be explained at present. The isolated cyanotic attack has never been lethal in my experience. Although treatment may be unnecessary the infant's appearance is so alarming that action is always taken. A clear airway is assured and then sensory or chemical stimulation of respiration is added and oxygen is given temporarily. Such treatment is about as scientific as shaking a clock which has stopped, but fortunately the mechanism is intact and requires no more drastic remedy.

\section{Some Factors which Influence Progress}

Birth Weight. (Fig. 4). The influence of birth weight upon the progress of the live-born baby of the diabetic woman is apparent from Fig. 4. The curve of mean birth weight at varying gestational ages, the latter based on the date of the last menstrual period, is derived from the figures of Ellis (1951). Dyspnoea and death were commoner among the lighter babies at any gestational age, or among babies of $1,700 \mathrm{~g}$. birth weight or less. Uncom- 


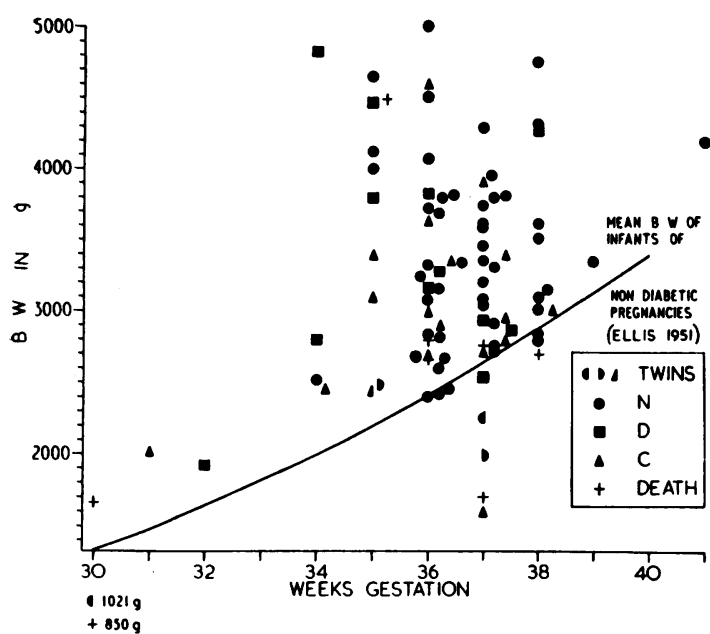

FIG. 4.-Birth weight, maturity and clinical behaviour. $\mathbf{N}=$ Normal. $\quad \mathbf{D}=$ Dyspnoea. $\quad \mathbf{C}=$ Cyanotic attack(s).

plicated cyanotic attacks were also commoner among the lighter babies. Only one baby of over 3,000 g. (6. 6 lb.) birth weight died.

Influence of Caesarean Section (Fig. 5). A higher morbidity and mortality exists among infants born to non-diabetic women by caesarean section than among infants of comparable maturity born spontaneously. This may result from the maternal or foetal illness which dictated the need for section or from circulatory stresses imposed by the method of delivery. A comparison was made between infants of the same maturity born by elective caesarean section to groups of diabetic and non-diabetic women who had not been in established labour. Both groups of women were patients in the same hospital between 1948 and 1955 . Three infants born to diabetic women died, but of these one had suffered pre-natal exsanguination and another had very severe erythroblastosis foetalis and kernikterus. They have been excluded from consideration in Fig. 5 as in neither case was death a result of diabetes mellitus or caesarean section. The third child died of pulmonary haemorrhage. Mortality and certainly morbidity were significantly higher among the infants of diabetic women than among those of the control group. The former were, however, observed more carefully and some cyanotic attacks may have passed unnoticed among the normal babies (Fig. 5). The comparison strongly suggests that diabetes and not caesarean section is the principal harmful influence.

Diabetic Control and Severity (Figs. 6 and 7). Control of the mother's diabetes has been graded

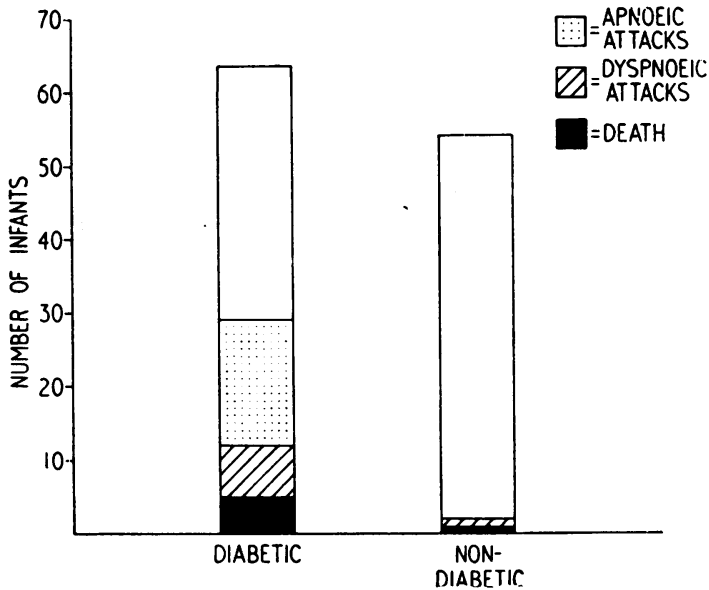

FIG. 5.-Mortality and morbidity among babies born prematurely at 35-38 weeks by caesarean section to women not in labour.

for me by the two physicians concerned during the eight-year period. Good control implies that the patients were free from symptoms, were not ketotic at any time and that the blood sugar determined weekly three hours or more after a meal never exceeded $140 \mathrm{mg} . \%$. Control is classed as bad if the patient had two or more ketotic episodes of 24 hours' duration or longer during the pregnancy or if the weekly blood sugar taken three hours or more after a meal exceeded $250 \mathrm{mg}$. \% on more than one occasion. Fair control describes those who were to be found somewhere between the two other

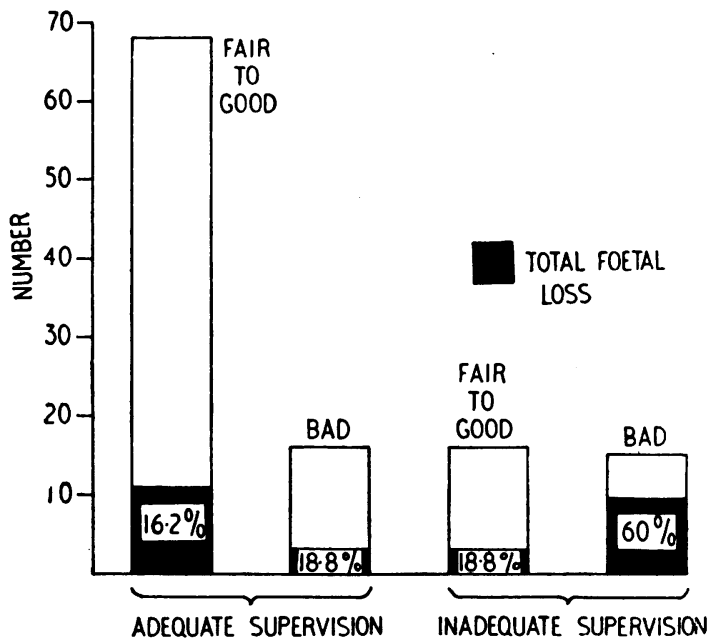

FIG. 6.-The influence of diabetic control upon foetal loss. The 115 cases are divided into two groups according to the standard of diabetic control, 'fair to good' and 'bad'. These are further subdivided according to the adequacy of ante-natal obstetric supervision. 


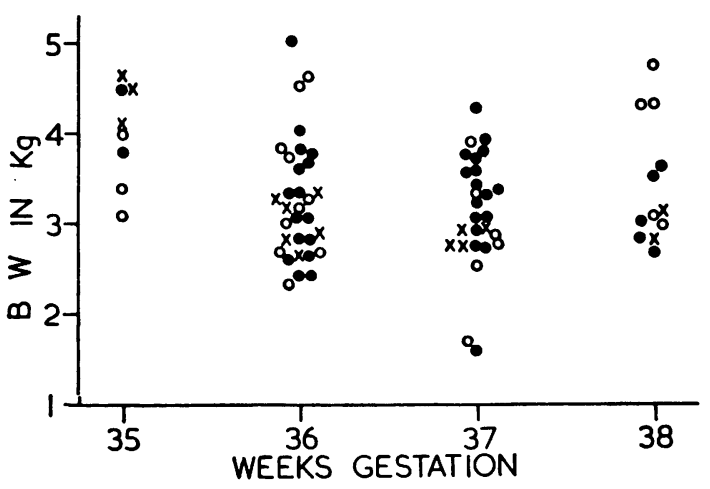

FIG. 7.-The influence of diabetic control upon birth weight. $\sqrt{2}$ Control: $\mathrm{O}=$ Good. $=$ Fair. $\times=$ Poor.

groups. In the present series poor control carried an increased risk to the foetus (Fig. 6) which became disastrous when linked with inadequate antenatal obstetric care.

From the data available in this study no clear influence of diabetic control on birth weight is apparent (Fig. 7) but a suggestion exists that as pregnancy proceeds toward term poor control adversely influences foetal growth. Certainly the large recent study of White Class F diabetic mothers (those with nephropathy) by Oppé, Hsia and Gellis (1957) quoted a viable foetal mortality exceeding $50 \%$ for such as compared with the $18 \%$ loss for the less severely affected women (Table 1) and the babies of the Class F group were found to be smaller.

Family Birth Weight (Fig. 8). The birth weights and the maturity of all sibs of the children in this series were ascertained wherever the information was available, and these were grouped in families. In order that the diagram may be more easily understood it has been subdivided into 12 small graphs with three or four families on each. The number allotted to each family is the number of the first case in that family to be included in the present series. The point at which the mother was found to have diabetes mellitus is indicated on the horizontal axis of each small graph and the years before and after read to the left and right from there.

The horizontal broken line on each graph indicates $4.0 \mathrm{~kg}$. $(8.8 \mathrm{lb}$.) birth weight. The only children of diabetic women are naturally excluded.

The birth of heavy babies during the pre-diabetic years is as apparent here as it was in the series studied by Miller, Hurwitz and Kuder (1944), Gilbert (1949) and Futcher and Long (1954). Many of these large babies in the present series are shown to be sibs.

Maternal Build (Fig. 9). The birth weight group of only children in the series has been plotted against the maternal height and weight prior to the onset of pregnancy. In the case of families composed of more than one child the average birth weight in all the children has been plotted against the height and weight prior to the onset of the last pregnancy. The weaknesses in this comparison are acknowledged. The infants vary in maturity, but the only children are mostly in the 36-38 week range and the majority of babies of multiparous diabetic women were delivered at term. The build of mothers of only children was in fact the build at the time of the child's birth, but in the case of multiparous women their weight when the last child was born does not necessarily represent their weight when child-bearing began. These points and the small size of the groups make impossible an analysis of such other possibly important factors as birth rank, maternal age and social group of the father.

No clear relationship exists between foetal birth weight and maternal build except that with some

TABLE 1

FOETAL MORTALITY IN THE DIABETIC PREGNANCY

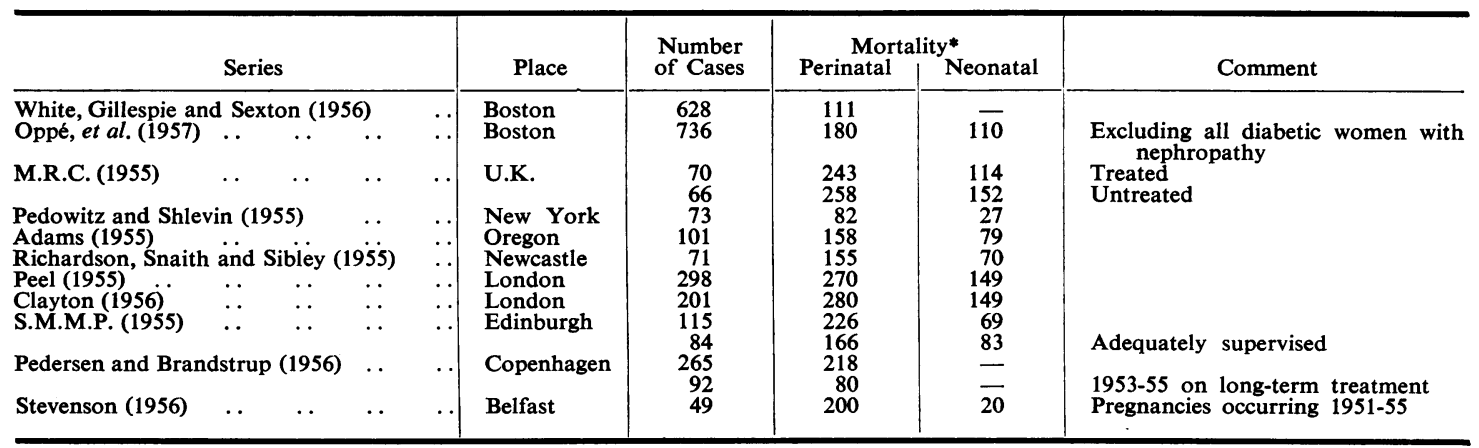

* Expressed in terms of per 1,000 viable pregnancies. 

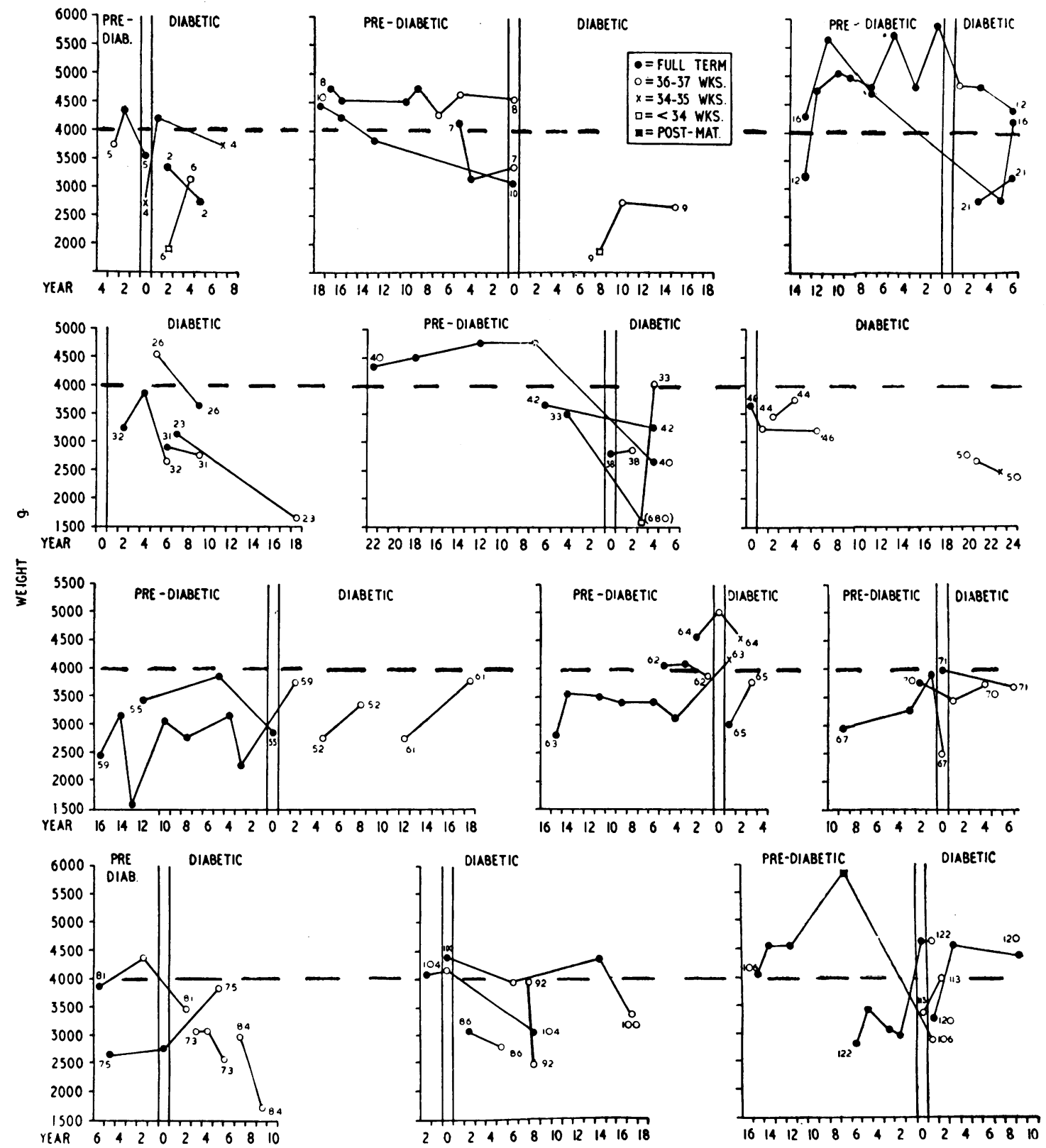

FIG. 8.-Family birthweights and the duration of maternal diabetes.

(The case numbers allow comparison with Fig. 10.) The figure 680 in the middle chart of the second line refers to a birthweight of $680 \mathrm{~g}$.

exceptions infants of less than $3.0 \mathrm{~kg}$. at birth appear to be commoner among lighter mothers. The birth of babies exceeding $4.0 \mathrm{~g}$. to short light diabetic women is unusual.

Family Mortalities (Fig. 10). In this figure the families are arranged in horizontal lines. The prediabetic and diabetic years of the mother's life are again indicated. The fate of the foetus is shown by symbols. The viable foetal loss of 121 per 1,000 during the pre-diabetic years compares with 195 per 1,000 after the establishment of clinical diabetes. The neonatal death rates* of 61 and 69 per 1,000

* Neonatal deaths are expressed here not in terms of per 1,000 live births but of per 1,000 viable pregnancies. 
viable pregnancies are less obviously different. Neonatal deaths among diabetic primipara, however, number 77 per 1,000 . These figures suggest that mortality rises with the development of clinical diabetes, and when the 23 multiparous mothers who were diabetic in each pregnancy are considered, the viable foetal loss is 236 per 1,000 and the neonatal deaths are 73 per 1,000 . These figures are contrasted in turn with the results of 54 viable pregnancies among eight women whose child-bearing began at least 10 years before the development of diabetes mellitus. Only six of these babies died, and of these five were neonatal deaths, which give a viable foetal loss of 111 per 1,000 and the neonatal death rate is 93 per 1,000 . The very low incidence of intra-uterine death contrasts with the situation after clinical diabetes appears. The high neonatal death rate occurred at a time when the rate was significantly higher than now among the general newborn population. The families were mostly big ones and social conditions may have been adverse.

Mortality and Foetal Birth Weight in the PreDiabetic Group (Table 2). The groups of mothers

TABLE 2

BIRTHWEIGHTS OF CHILDREN BORN TO PRE-DIABETIC WOMEN

\begin{tabular}{|c|c|c|c|}
\hline \multirow[b]{2}{*}{ Family } & \multicolumn{2}{|c|}{ No. of Children } & \multirow[b]{2}{*}{$\begin{array}{l}\text { Birthweight } \\
\text { Trend }\end{array}$} \\
\hline & $\begin{array}{l}\text { Weights } \\
\text { Known }\end{array}$ & $\begin{array}{l}4.0 \mathrm{~kg} . \\
\text { or more }\end{array}$ & \\
\hline $\begin{array}{r}8 \\
10 \\
12 \\
16 \\
40 \\
59 \\
63\end{array}$ & $\begin{array}{r}7 \\
4 \\
11 \\
5 \\
5 \\
5 \\
8 \\
7\end{array}$ & $\begin{array}{r}7 \\
2 \\
10 \\
4 \\
4 \\
0 \\
1\end{array}$ & $\begin{array}{l}\text { Sustained } \\
\text { Downward } \\
\text { Sustained } \\
\text { Only 4th less than } 4 \mathrm{~kg} \text {. } \\
\text { Only last below } 4 \mathrm{~kg} \text {. } \\
\text { Upward } \\
\text { Only last below } 4 \mathrm{~kg} \text {. }\end{array}$ \\
\hline 106 & 5 & 4 & $\begin{array}{l}\text { Only last below } 4 \mathrm{~kg} \text {. } \\
(37 \text { wk.) }\end{array}$ \\
\hline Total & 52 & 32 & \\
\hline
\end{tabular}

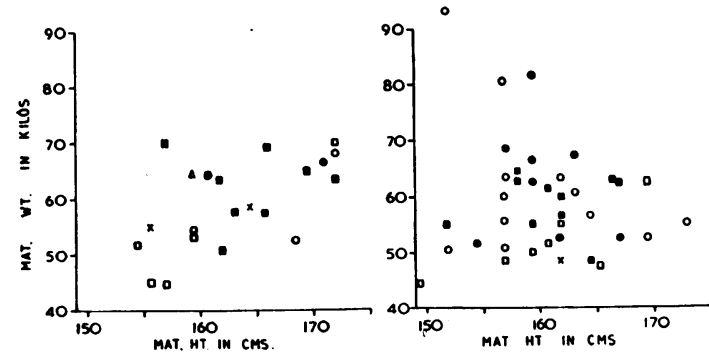

FIG. 9.-The relationship of maternal build to foetal birthweight. Foetal birthweights: $=4 \mathrm{~kg}$. or more. $\mathrm{O}=3.5 \mathrm{~kg}$. but less than 4. $\square=3 \mathrm{~kg}$. but less than $3 \cdot 5 . \square=2 \cdot 5 \mathrm{~kg}$. but less than 3 . $X=2 \mathrm{~kg}$. but less than $2 \cdot 5$. $\Delta=$ less than $2 \mathrm{~kg}$. whose child-bearing life began at least 10 years before diabetes was diagnosed, bore a remarkable number of large babies. The birth weights of 52 of them are known, and of these, 32 weighed $4.0 \mathrm{~kg}$. or more at birth.

Thus those mothers who developed diabetes after their first child was at least 10 years old not only produced the typical large babies of diabetic women but they did so at the cost of comparatively few lives and with less than $2 \%$ of intra-uterine deaths. This fact is complementary to that apparent in Fig. 3, i.e. that death and dyspnoea are commoner among the smaller infants at any gestational age. The growth promoting and the lethal influences upon the foetus are not therefore necessarily identical.

\section{Pathology}

Infants born to diabetic women show anatomical and histological abnormalities which have been described in detail by Cardell (1953). These include gigantism, visceromegaly and significant changes in

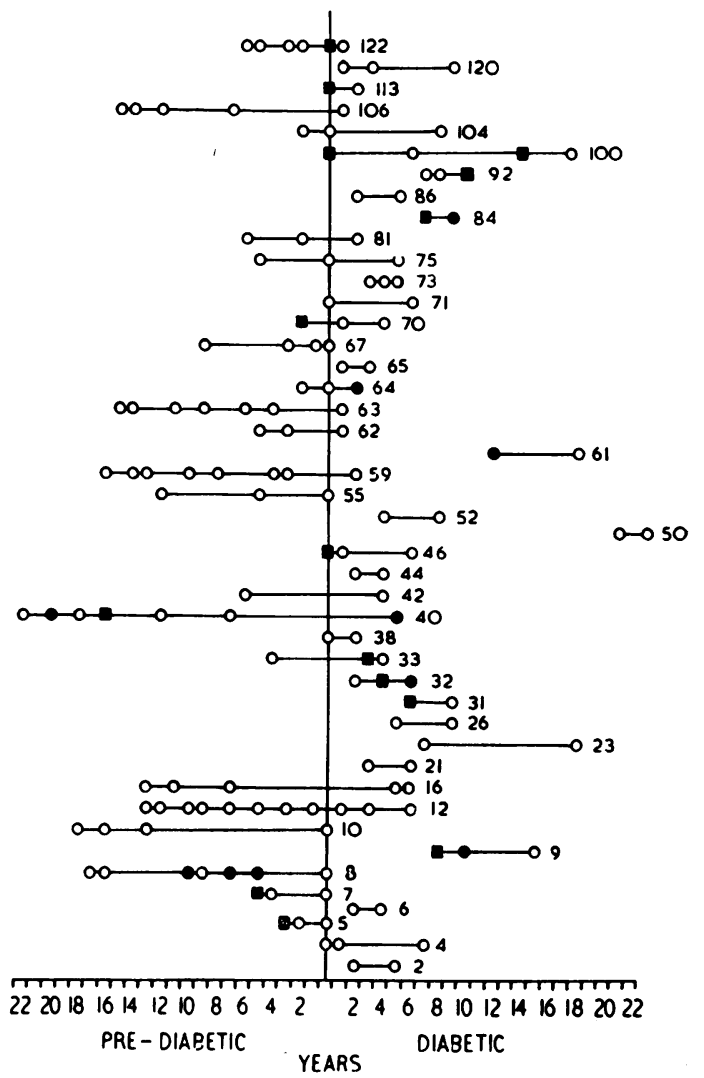

FIG. 10.-Family mortalities and the duration of maternal diabetes. $\mathbf{O}=$ survival. $=$ N.N.D. $\quad=$ I.U.B. (The case numbers allow comparison with Fig. 8.) 
TABLE 3

PRINCIPAL AUTOPSY FINDINGS

\begin{tabular}{c|c|c|c|c}
\hline Case No. & $\begin{array}{c}\text { Maturity } \\
\text { (weeks) }\end{array}$ & $\begin{array}{c}\text { Birthweight } \\
\text { (g.) }\end{array}$ & Nature of Delivery & Pneumonia. Terminal inhalation \\
\hline 9 & 37 & 2,764 & C/S & Massive adrenal haemorrhage \\
\hline 18 & 36 & 2,807 & Breech. Forceps to head & Hyaline membrane \\
\hline 32 & 36 & 2,651 & Intracranial haemorrhage \\
\hline 35 & 30 & 1,644 & Signs of asphyxia \\
\hline 40 & 38 & 2,693 & C/S & Massive cerebral haemorrhage. Hyaline membrane \\
\hline 84 & 37 & 1,701 & Spontaneous twin breech & Atelectasis. Prematurity \\
\hline $93 B$ & 30 & C/S & Renal thrombosis \\
\hline 102 & 35 & 4,508 & & \\
\hline
\end{tabular}

endocrine glands. Over 20 reports of pancreatic islet hyperplasia in such babies are quoted by Pedersen (1952), and these have been substantiated by the quantitative studies of Tejning (1947), Beek (1952) and by Cardell who showed that the beta cells are chiefly involved and that a positive direct correlation exists between the volume of islet tissue and the size of the baby. Enlargement of the adrenal glands involves principally the cortex, and cardiomegaly, with some increase in myocardial glycogen, is common. The commonest autopsy finding in most series is pulmonary hyaline membrane. Renal vein thrombosis occurs rarely (Tveterås and Rudström, 1956; Avery, Oppenheimer and Gordon, 1957).

Autopsies have been carried out by Dr. Agnes Macgregor on all eight deaths in this series and the principal findings are given in Table 3 . Only the pneumonic death was preventable. Extreme prematurity cannot always be avoided, but breech delivery was not permitted after 1949. Islet hyperplasia was reported in the pancreas of each case by Dr. R. F. Ogilvie.

\section{Metabolic Abnormalities of the Foetus}

The problems relating to the collection of specimens increase the difficulty of metabolic investigation at this age. The principal abnormalities described concern potassium, calcium and glucose.

Potassium. According to Björklund (1953) the serum potassium of babies born to diabetic women is low, and he found 'suppression or sagging' of the S-T segment, pathological negative $T$ and $U$ waves and prolongation of the QT interval on their electrocardiograms, but no such changes in a control group. They existed whether the baby showed clinical disturbance or not, but in no abnormal baby was the E.C.G. normal. Such E.C.G. changes in adults have been ascribed to potassium deficiency.

Depression or sagging of the S-T segment was apparent in nine of 11 E.C.G. tracings obtained from babies in the present series. Some of the infants were asymptomatic and others who were dyspnoeic showed no other evidence of potassium deficiency. The $\mathbf{T}$ wave abnormalities at this age are not believed to be specific of hypokalaemia but may represent a metabolic disorder. Depression or inversion of the $T$ waves is more likely to relate to intracellular potassium levels than to serum levels and McCance (1955) does not believe that they truly reflect potassium lack. No evidence exists for giving such infants potassium and it may be dangerous. In one clinic where parenteral potassium has been given the neonatal mortality is higher than in the Edinburgh series.

Calcium. Low serum calcium levels in infants born to diabetic women and in premature babies of non-diabetic women have been reported by Craig and Buchanan (1958). The babies in the diabetic group were mostly prematurely born. The levels recorded are certainly below the accepted normal range and the authors suggest that the neuromuscular irritability of these infants on the second and later days of life may be hypocalcaemic tetany, a condition which bears little resemblance to tetany in the more mature subject (Talbot, Sobel, McArthur and Crawford, 1952; Wilkins, 1957). Unfortunately the series includes no proper control study so that there is no real evidence that the low calcium levels are directly responsible for symptoms. No suggestion has been made that dyspnoea or cyanotic attacks are of hypocalcaemic origin. The infants studied by Farquhar and Smith (1958) during exchange transfusion for haemolytic disease did not show increased neuromuscular irritability even at 
very low levels of calcium ion. Calcium was not found by Craig and Buchanan (1958) to relieve the neuromuscular irritability of the babies of diabetic women and better results were obtained with chloral hydrate.

No serum calcium determinations were made on the infants in the present series.

Glucose. The blood sugar falls more consistently, more rapidly and further in infants born to diabetic mothers than in normal babies of non-diabetic mothers. This hypoglycaemia is at its height at 2-3 hours and it is corrected spontaneously in 4-6 hours. No correlation exists between the speed of fall, the lowest level reached, the development of symptoms or later progress (Farquhar, 1954, 1956a). The minute volume of expired air, measured in a small number of babies, did not vary significantly in the first few hours. During the years 1948-51 glucose was given by mouth or by injection to infants of diabetic mothers in doses roughly equivalent to those used in glucose tolerance tests, in an attempt to prevent hypoglycaemia. Even with this precaution the blood sugar tended to fall (Table 4).

\section{Maternal Diabetes and Foetal Abnormality}

Morphology of the Foetus. The diabetic woman exerts influences upon her baby which accelerate growth, stimulate hypertrophy of the pancreatic islets and particularly of the beta cells, provoke increased formation of glycogen in at least some infants and a sharp fall in blood sugar beyond the

\section{TABLE 4}

BLOOD SUGAR LEVEL RESPONSE IN INFANTS OF DIABETIC WOMEN TO THE ADMINISTRATION OF GLUCOSE IN THE FIRST 6 HOURS OF LIFE

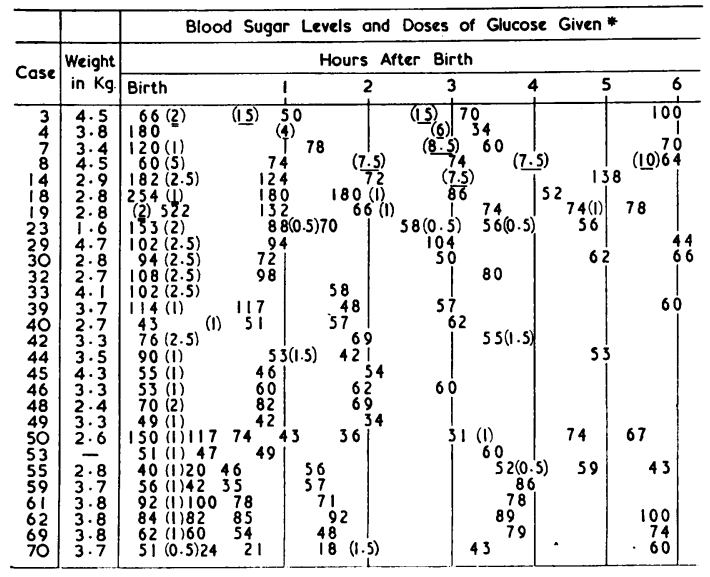

* The figures in brackets represent grammes of glucose given. Where underlined once the oral route of administration was used, where underlined twice the dose was intravenous. Otherwise the glucose was given by intramuscular injection. normal range in almost all. The increased pancreatic beta cells can reasonably be expected to produce increased amounts of insulin. They do not appear to be a different 'foetal tissue' analogous to the foetal adrenal cortex with activities confined only to pre-natal life. If they do not secrete more insulin then it is difficult to imagine what other function such specialized cells can perform or to believe that the insulin mechanism is the victim of an intrinsic metabolic block similar to the enzyme defects existent in some forms of goitrous cretinism.

The impression gained in the present study is that these babies tolerate glucose abnormally well in the first few hours but that the situation rapidly alters. Against this may be set the apparently definite conclusions of Read (1951) but serious faults are present in his study. Enough circumstantial evidence exists to justify the belief that the immediate post-natal hypoglycaemia of infants born to diabetic women results from increased foetal insulin secretion and that separation of the infant from the maternal circulation ends the pancreatrophic influence. Moreover, although the pancreatic islet hyperplasia has been shown only in fatal cases, these babies did die of causes other than hypoglycaemia, and almost all surviving babies have been hypoglycaemic so that pancreatic hyperplasia at birth can be assumed to exist among survivors.

Foetal hyperinsulinism may be stimulated by maternal hyperglycaemia, pituitary growth hormone or corticosteroids or by the baby's adrenocortical response to maternal corticotrophin. The occurrence of gigantism and pancreatic islet hyperplasia in babies of pre-diabetic women means that high maternal blood sugar levels are not responsible for these abnormalities by themselves. The suspected role of pituitary growth hormone (P.G.H.) in the production of human diabetes mellitus has received support from the observations of Luft, Ikkos, Gemzell and Olivecrona (1958) that such material purified from human pituitary glands provokes rapid hyperglycaemia and ketosis in young hypophysectomized diabetic human adults. This hormone, in amounts insufficient to cause maternal acromegaly, may very well stimulate the foetal pancreas and accelerate the growth of already rapidly growing foetal tissue. According to Ikkos, Luft and Gemzell (1958) P.G.H. may also cause some increase in salt retention and in the extracellular volume. It could explain, therefore, the slight fluid retention suspected in babies of diabetic women.

Adrenal corticosteroids may also stimulate the pancreatic islets, as in Cushing's syndrome, and cause fluid retention. Their production is increased in young diabetics (Klein, Papadatos, Fortunato and 
Byers, 1955; Klein, Weigand, Iunes and Greenman, 1956; Grayzel, Warshall, Elkan and Sternberg, 1957) and in pregnancy (Cope, Boysen and McCrae, 1951). There is some evidence, however, that they may not pass the placental barrier, whereas corticotrophin may do so (Farquhar, 1956b). If such is the case then maternal corticotrophin may increase the pancreatrophic influence by stimulating the foetal adrenal cortex.

Evidence for foetal hyperadrenocorticism has been sought in studies of post-natal weight loss, urine volume and formaldehydogenic steroid excretion. The post-natal weight loss is proportionate to the delay in allowing the baby to feed but is no different in infants of diabetic and non-diabetic women (Farquhar and Sklaroff, 1958). The babies of the present series did, however, excrete rather more urine during the first 24-48 hours of life than infants born either by caesarean section or spontaneously to non-diabetic women (Table 5).

Eosinophil studies have provided no positive evidence of foetal hyperadrenocorticism (Farquhar, $1954,1955,1956 \mathrm{~b})$. The babies in the present series delivered by caesarean section to diabetic women excreted more urinary acid-stable formaldehydogenic steroids than normal infants of almost comparable maturity born by the same route or by the vagina (Fig. 11) The method of Tompsett and

INFANTS OF DIABETIC WOMEN

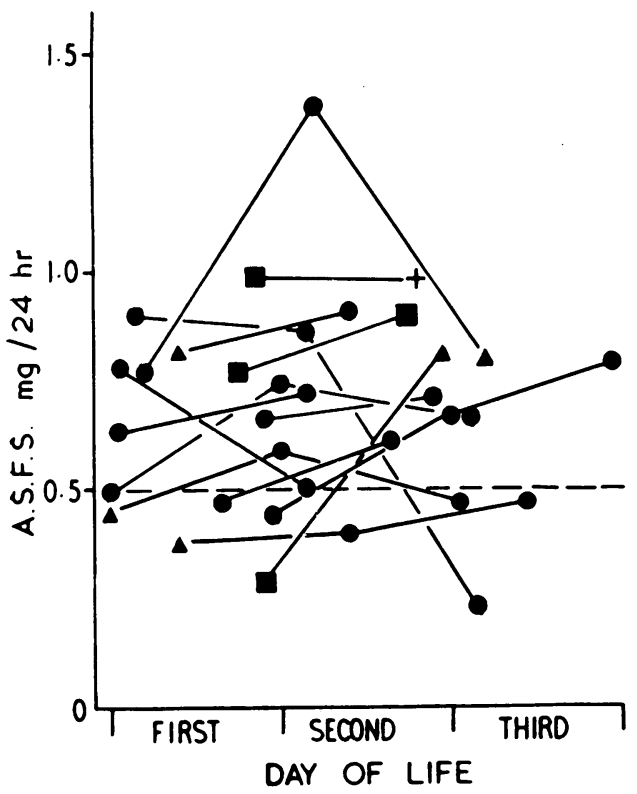

TABLE 5

TWENTY-FOUR HOUR URINE VOLUMES OF BABIES BORN TO DIABETIC AND NON-DIABETIC WOMEN

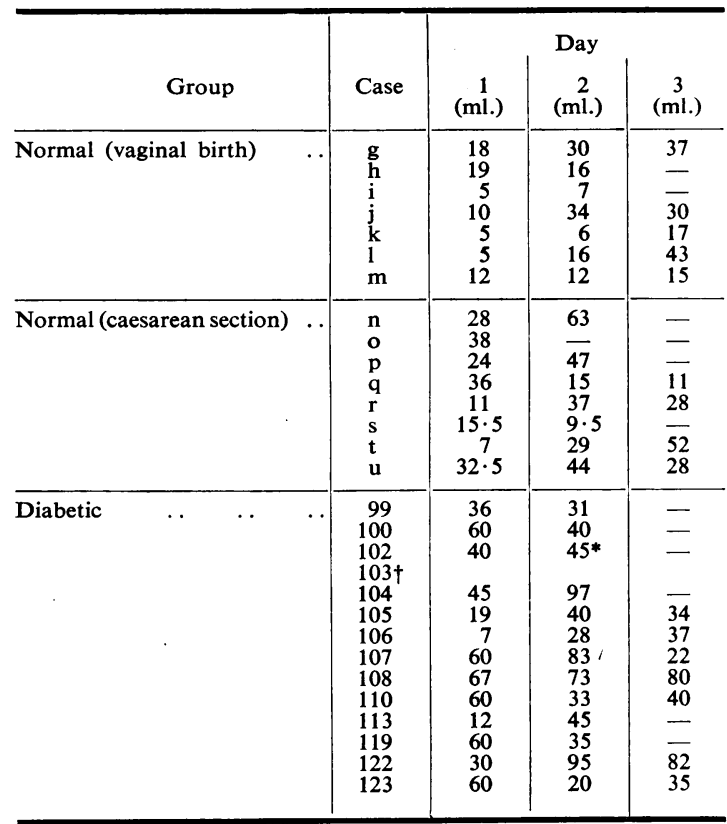

* In 16 hours (baby died).

$\dagger$ Record lost.

INFANTS OF NORMAL WOMEN

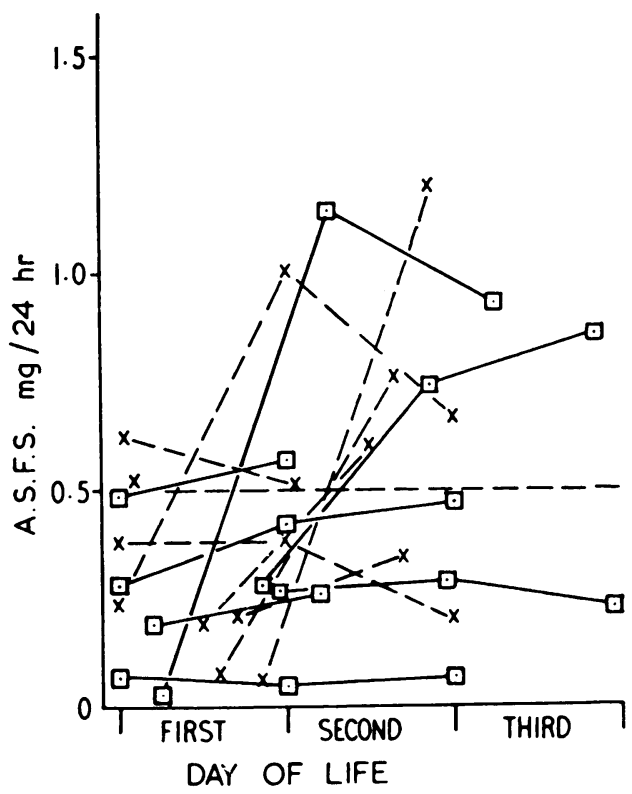

FIG. 11.-Serial daily urinary excretion of acid-stable formaldehydogenic steroids.

Diabetic: $=$ Normal. $=$ Dyspnoea. $\quad=$ Cyanotic attacks. $+=$ Death

Normal: $\square=$ Vaginal deliveries. $\quad \times=$ Caesarean sections. 
Smith (1954) was used. The principal limitation of formaldehydogenic steroid methods appears to be their failure to measure all the urinary corticosteroids (Marrian, 1951). This finding is in accord with the observations of Hoet (1954) who believes that hyperadrenocorticism plays some part in the morphology and morbidity of such babies.

Pathology of the Foetus. Pulmonary hyaline membrane, although found in only two of the eight $(25 \%)$ autopsies performed in this series, occurred in $80 \%$ or more of neonatal deaths in the large diabetic series of White (1952), Peel (1955) and Clayton (1956). A reversible degree of this abnormality may be the explanation of dyspnoea with survival in other babies. It is so common a finding that a knowledge of its cause may shed light on the whole problem of perinatal and neonatal morbidity in infants of diabetic women and on diabetes mellitus itself. The work done recently in a number of fields may indicate this. Migration of up to $25 \%$ of the plasma from the capillaries into the extravascular space in the first hours after delivery is physiological in the normal newborn baby (Gairdner, Marks, Roscoe and Brettell, 1958) and in the premature (Baar, 1956). The pulmonary resistance in newborn lambs is high before the lungs expand, and may be increased by tying the cord before respiration is established (Dawes, Mott, Widdicombe and Wyatt, 1953; Born, Dawes, Mott and Widdicombe, 1954). The electronmicroscopy studies of Van Breemen, Neustein and Bruns (1957) have confirmed that the hyaline membrane consists of blood plasma which has leaked from the vascular compartment, and that this is made possible by visible changes in the epithelial linings of ducts and alveoli and in the endothelial lining of capillaries. The infant of the diabetic woman is usually born prematurely and his cord is commonly clamped before the onset of respiration. If perinatal hypoxia could be proved this might represent the cause of capillary damage in the lungs and elsewhere. and it would contribute toward pulmonary hypertension.

Placental Dysfunction. The placenta of the diabetic woman is not obviously abnormal on inspection. It has been described as large by White (1952) and Peel (1955) believes that intrauterine death is due to the foetus outgrowing the efficiency of the placenta. The ratio of placental to foetal weight is normal in the present series (Fig. 12). If the foetus is large for gestational age so is the placenta, and no relationship can be found between the ratio and the clinical state of the foetus. Much has been said by White and her colleagues about hormonal changes associated with placental failure in the diabetic pregnancy, and good results have been claimed by them for hormone replacement therapy, but these have not been confirmed consistently in other American clinics nor by any in the United Kingdom. Most of those who have examined the histology of diabetic placentae have failed to demonstrate abnormalities which do not occur with equal frequency in the placentae of non-diabetic women (Reis, De Costa and Allweiss, 1950). Abnormal stromal oedema in diabetic placentae was observed, however, by Mackay of the Joslin Clinic (reported by White, 1952) when the tissue was carefully fixed within 30 minutes of birth. The oedema was not found in the placentae of non-diabetic women.

The vigorous erythropoiesis and the normoblastaemia of babies born to diabetic women led Berglund and Zetterström (1954) to believe that these infants suffered from pre-natal hypoxia and their investigation of the oxygen saturation of cord blood seemed to confirm this. Much attention has been paid recently to the dwindling supply of oxygen available to the foetus in late normal or in abnormal pregnancy (Walker and Turnbull, 1953; Walker, 1954; Turnbull and Baird, 1957; MacKay, 1957). The oxygen available to a number of babies in the present series was determined by MacKay (1955) and the results have been plotted in Fig. 13 with an indication of the anaesthetic employed at caesarean section and of the mean values found by her for normal pregnancies. No obvious relationship exists between the oxygen saturation per cent. and the later clinical behaviour of the foetus. Such oxygen levels

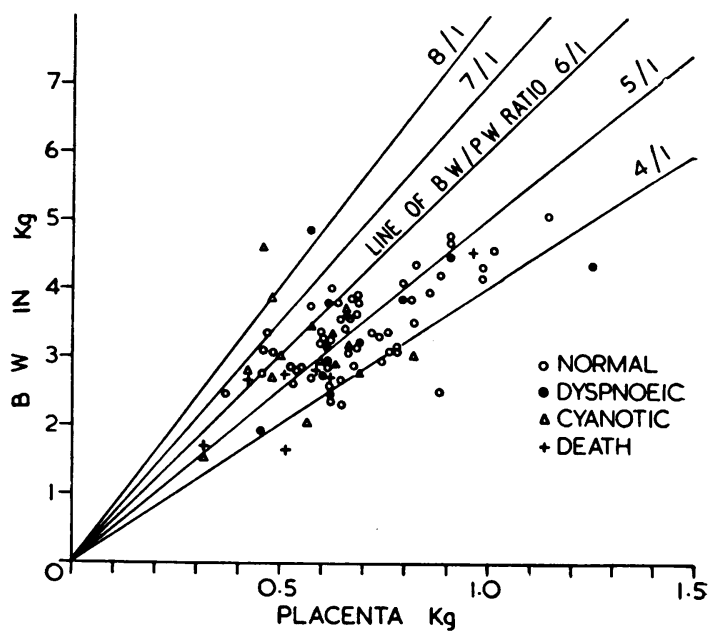

FIG. 12.-The relationship of foetal/placental weight ratio to clinical course. (Twins excluded.) 


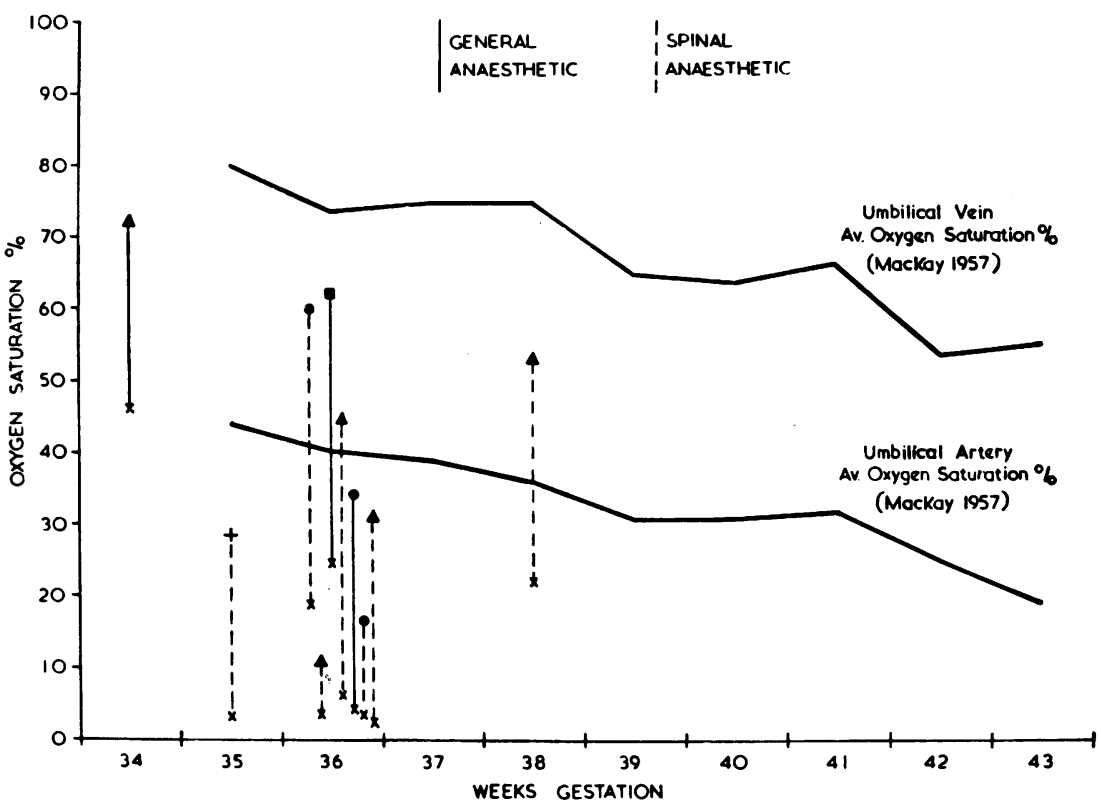

FIG. 13.-Oxygen saturation of umbilical cord blood at delivery of diabetic women. (The average values refer to normal pregnancies.) Umbilical vein: $\mathbf{O}=$ Normal. $\Delta=$ Cyanotic attacks. $\mathbf{a}=$ Dyspnoea. $+=$ Death Umbilical artery: $=\times$.

may not represent the true situation, however, but only the conditions prevailing after delivery of the foetus. The oxygen pressure gradient across the haemochorial human placenta may indicate the infant's available oxygen more accurately, and Prystowsky (1957) has shown that it falls significantly in abnormal, including diabetic, pregnancy. These observations strongly suggest that perinatal hypoxia exists in diabetic pregnancy and that this may cause intra-uterine or neonatal death, or respiratory distress with survival.

The chorionic villi, which share a common origin with the foetus, respond in the same way to the growth-promoting influence. In many pregnancies the larger placenta supplies a larger foetus, but in others it becomes unhealthy at about the thirtysecond week with resulting retardation of foetal growth and increased risk. When it fails later the foetus is already large and sudden intra-uterine death may result from the relatively greater deficiency. P.G.H. may accelerate the life of the placenta and so shorten its limited span, but the lower mortality among the large babies of prediabetic mothers does not support this. Microscopic degenerative changes have been shown by Ditzel and Moinat (1957) to develop in the conjunctival capillaries of diabetic women in later pregnancy and these can be related to inadequacy of diabetic control. Can the premature placental degeneration of diabetes mellitus be related to the vascular degeneration of this disease? That the latter may be caused by adrenal corticosteroids has been suggested by Becker (1952) Becker, MaengwynDavies, Rosen, Friedenwald and Winter (1954), Williams (1955), and, with less certainty, by Maengwyn-Davies, Lerman, Pogell, Stone and Friedenwald (1956). This suggestion has received no support from the work of Rifkin, Solomon and Lieberman (1958) but further work on the possible role of individual normal or abnormal corticosteroids continues. The infants of this series seemed to excrete increased amounts of formaldehydogenic steroids. The occurrence of classical vascular degeneration in cases of pure pancreatic diabetes (Lawrence, 1950; Duncan, MacFarlane and Robson, 1958) supports the belief that it may result from the metabolic disorder caused by insulin deficiency and that an inherited vulnerability or dyspituitarism are not necessarily involved. Insulin deficiency, however, is unlikely to be responsible for the foetal deaths during the mother's pre-diabetic years, and it is interesting to recall that in Fig. 10 intra-uterine deaths are less common before the development of clinical diabetes. Strict diabetic control is now advocated as the only way in which vascular degeneration may be prevented or delayed (Dunlop, 
1954) and whether similar changes in the placenta are the result of insulin deficiency, corticosteroids or an as yet undetermined factor, strict diabetic control in pregnancy and good obstetrics are the only ways by which the foetal mortality can be reduced (Pedersen and Brandstrup, 1956).

\section{Treatment of the Newborn}

The treatment of the newborn consists of gentle resuscitation and continuous observation in a warm room for four days or more. Although routine gastric aspiration at birth has been practised, the large volumes of gastric content reported by Gellis, White and Pfeffer (1949) have not been found in our series (Fig. 14). Feeding should be delayed until the morning of the third day and possibly till later in small infants. Clear fluids only are given during the first day of feeding. Antibiotics and oxygen play no part in routine management. The hypoglycaemia does not require correction, the giving of potassium salts is probably both unnecessary and dangerous, and calcium has little effect on the neuromuscular irritability. Sedation is probably undesirable. Nursing supervision must be conscientious or dramatic cyanotic attacks may be missed by an inattentive nurse even sitting by the cot. The baby's pharynx should be gently aspirated before respiration is stimulated by flicking the baby's foot. Oxygen may be given for a few minutes. Chemical stimulation is rarely necessary.

The treatment of the dyspnoeic syndrome is unsatisfactory. Oxygen may be given in concentrations not exceeding $35 \%$, but water-vapour mists have been shown to be ineffective (Hsia, Peterson and Gellis, 1957). The babies should not be disturbed unless to aspirate mucus. Assisted respira-

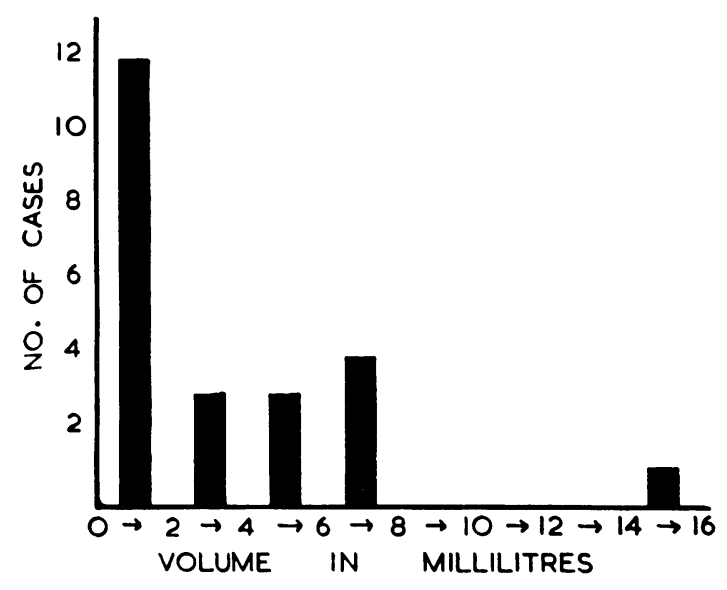

Fig. 14.-The volume of gastric contents at birth. tion by mechanical means may help but it is less important than trying to prevent the hypoxia which precedes the membrane's formation. Strict diabetic control alone is the most effective preventive so far, particularly when it permits vaginal delivery at term. Minor skin infections, to which the babies seem predisposed, should be treated with aqueous gentian violet or, in severe cases, by the systemic use of the effective antibiotic.

\section{Lactation}

Normal lactation in diabetic women has been reported by Wilder and Parsons (1928), Merkler (1929) and Peckham (1931) but it is more commonly described as poor. It was deficient in all the cases reported by McIlroy, Hill and Pillman-Williams (1931), and in the experience of Peel (1951) only half these mothers are able to breast feed adequately. Lactation may start normally and then fail (Barns and Morgans, 1952) or it may be established only with difficulty but remain adequate afterwards (Peel and Oakley, 1950).

Inadequate maternal nutrition was held to be responsible by Skipper (1933) and to be partly responsible by Sheumack (1949). Not all such mothers are obviously malnourished now and the improvement in diabetic nutrition is the recognized explanation for the altered fertility among such women. Premature delivery may be partly responsible (Peel 1951; Barns and Morgans, 1952; Rolland, 1954). An immature baby certainly may provide poor stimulation for the breast even if suckling were permitted during the first few days. The lactation even of non-diabetic women, however, is established more slowly after caesarean than after spontaneous delivery. Prolactin deficiency is suspected by Sheumack (1949) and a pituitary abnormality by Peel (1951).

The breast feeding history of 60 non-diabetic women who were delivered by caesarean section has been studied (Fig. 15, inset). Half of them were breast feeding their babies fully at discharge from hospital and only a third had failed completely. The composition of this group of infants has already been described (Farquhar and Sklaroff, 1958) and differs mainly by being rather more mature than the diabetic group. In contrast to this the breast feeding history of diabetic women, most of whom had been delivered by caesarean section, in the present series is poor (Fig. 15). Considerably more than half the women either abandoned the attempt in the first week, or less commonly no attempt was made. A further large group failed during the first 4 to 6 weeks. Some, however, were fully or partly success- 


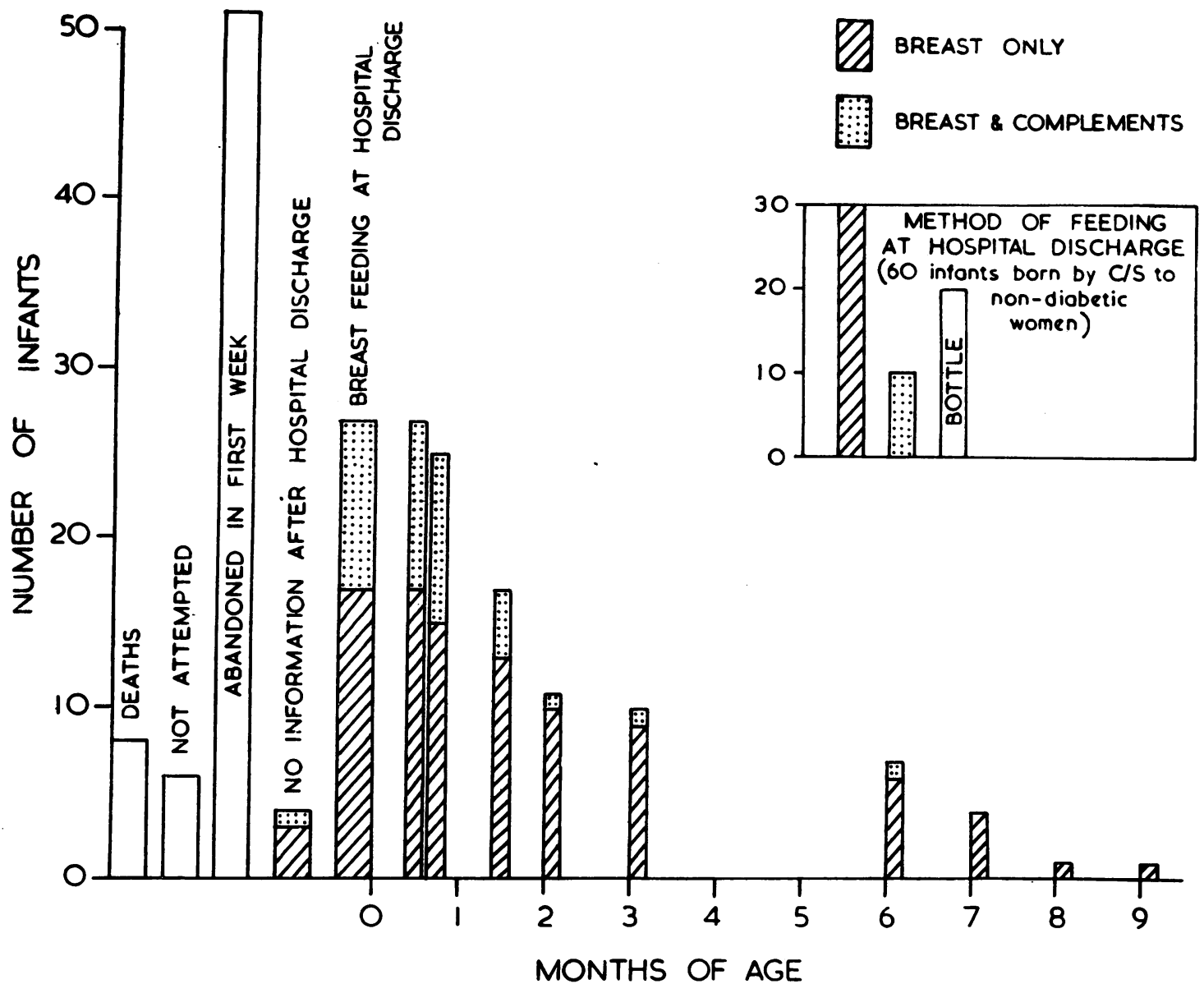

FIG. 15.-The breast feeding history of 96 infants born to diabetic women.

ful until weaning was established at 6 to 9 months of age. More detailed information about these groups is available from Table 6 . No consistent relationship has been found between the pre-diabetic and diabetic obstetric histories of the mothers or the size of the babies and the success or failure of breast feeding. Although the hypothesis that inadequate lactation is but one facet of a complicated metabolic disorder involving the pituitary no- convincing evidence for this has been advanced so far. Almost certainly more diabetic women could breast feed if every encouragement were provided. That she should do so is not, however, a matter of great consequence nowadays.

\section{Congenital Malformations}

Early this century, Herman (1902) referring to diabetic pregnancy stated that 'the chances are two to one that the child will die in utero. Its life is therefore not of much account'. With the improved survival rate, however, the fate of the survivors assumes greater importance.

The incidence of congenital malformations in those series which include 40 or more cases ranges from none (Patterson and Burnstein, 1949; Hall and Tillman, 1951) to $80 \%$ in the large Boston series (White, 1952). Most published series quote an incidence of from 2 to $3 \%$ but Barns and Morgans (1949) claimed 10\%, Peel and Oakley (1950) $63 \%$ and Hagbard (1956) 62\%. Fredrikson, Hagbard, Olow and Reinand (1957) found only one of 123 cases derived from a larger group of which they thought that many probably died earlier of malformation. Few of these authors examined a control group of babies born to non-diabetic women, and where they did so no description of the control 
material was given. Of all of these quite the most extraordinary contrast lies in White's claims of $\mathbf{8 0}$ and $1.8 \%$ of congenital malformations in babies born to diabetic and non-diabetic women respectively. Her statement (1949) that these anomalies were severe in only $10 \%$ and lethal in only $2 \%$ raises doubt as to whether she looked for the same range of abnormalities in the control group.

Several explanations can be found for these wide variations in incidence. Some authors may have included every trivial abnormality found on clinical examination, whereas others used technical aids to diagnosis or recorded only the lethal malformations discovered at autopsy. Some have mentioned only those anomalies which are obvious in the first week whereas others have followed their cases and have added those malformations which were discovered later. The nearest approach to a properly controlled study so far is probably that of Cardell (1953) who found incidences of $25 \%$ and $20 \cdot 2 \%$ at autopsy in babies of diabetic and non-diabetic women respectively. The difference was not considered significant. Abnormalities of the eye, such as congenital cataract, and of other systems may not always be apparent at autopsy.

Almost all of the surviving children in this series have been re-examined personally and compared with the same number of children who were born in the same hospital and whose non-diabetic mothers had been matched for the month and year of conceiving the child and for age and parity with the mothers in the diabetic group. A medical history was taken in each case and the children were submitted to a standard clinical examination. Technical investigations such as radiography were undertaken only if some positive lead existed, e.g. recurrent urinary infections, scoliosis. Only those malformations which were considered to be

TABLE 6

FEEDING RECORD OF 88 SURVIVING BABIES OF DIABETIC WOMEN

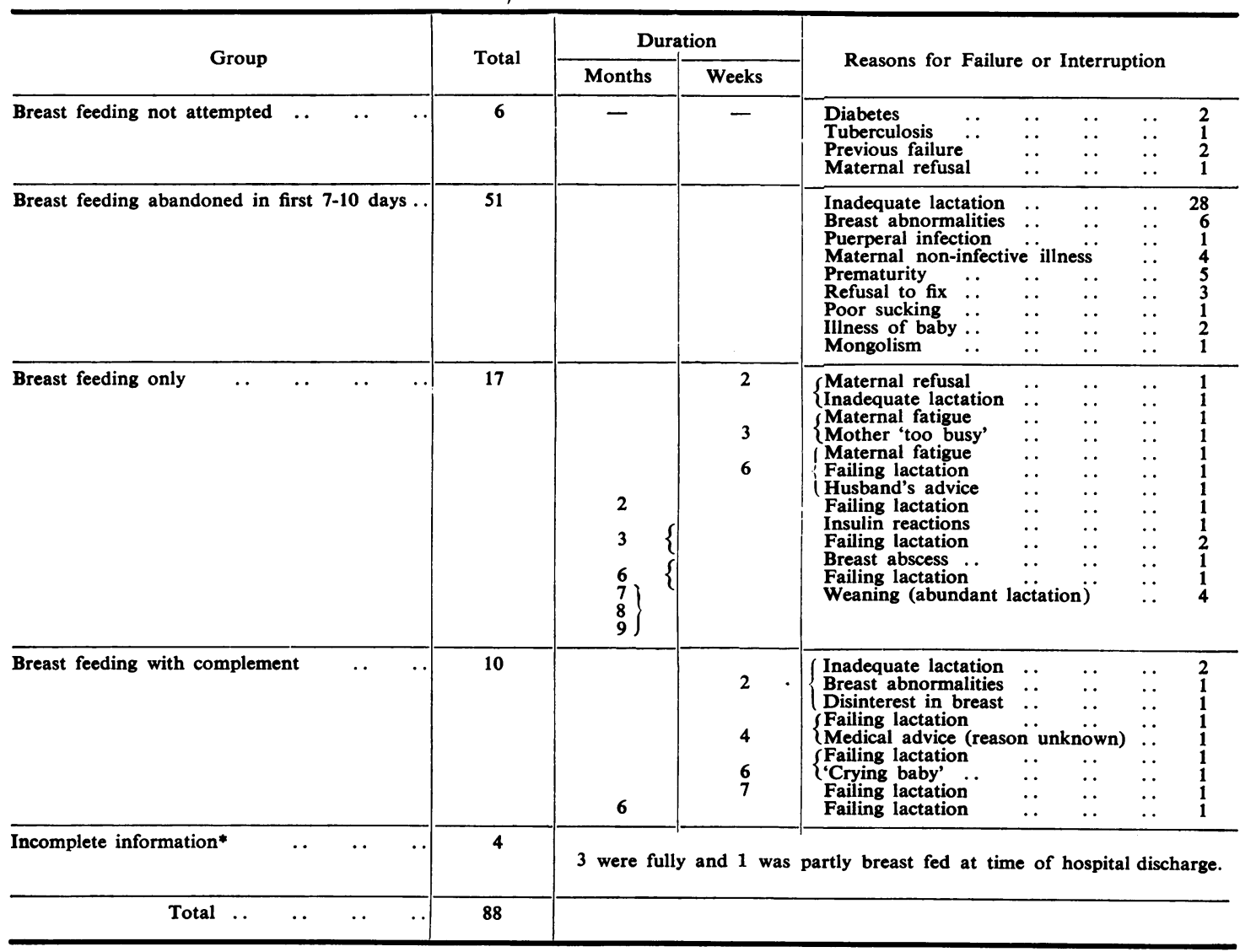

* Contact lost because of death of mother or child, or because of emigration or adoption. 
TABLE 7

PHYSICAL ABNORMALITIES PRESENT SINCE BIRTH*

\begin{tabular}{|c|c|c|}
\hline \multicolumn{2}{|c|}{ Diabetic Group (93) } & Non-diabetic Group (93) \\
\hline $\begin{array}{l}\text { Sacral agenesis } \ldots \\
\text { Congenital cataracts } \\
\text { Patent ductus arteriosus } \\
\text { Hydronephrosis } \quad \ldots \\
\text { Mongolism .. } \\
\text { Mental defect } \\
\text { Scoliosis (hemivert.) } \\
\text { Extra thumb } \\
\text { Fused central incisors }\end{array}$ & $\begin{array}{ll}\ldots & 1 \\
\cdots & 1 \\
\cdots & 1 \\
\cdots & 1 \\
\cdots & 1 \\
\cdots & 2 \\
\cdots & 1 \\
\cdots & 1 \\
\cdots & 1\end{array}$ & 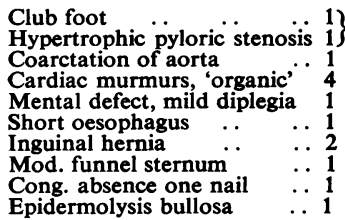 \\
\hline & 10 & (13 children) \\
\hline
\end{tabular}

* Groups matched for maternal age and parity and for month and year of delivery at S.M.M.P.

disabling, potentially disabling, in need of surgical correction, or disfiguring were included, and such trifling deformities as mild plagiocephaly, small pilonidal sinuses, prominent ears or small naevi normally covered by clothing were excluded. Little difference in incidence emerged between the two groups (Table 7) but in this comparatively small study the abnormalities in the diabetic group may be rather more severe. The recorded cardiac murmurs in the non-diabetic group were considered to be organic but, because the children were asymptomatic, no further investigation was undertaken except in the case of the child with aortic coarctation.

\section{Later Development}

Relationship of Neonatal Condition to Later Health. Almost all the surviving children in the series have been re-examined on at least one occasion at ages ranging from 2 to 10 years. Their progress is shown in Fig. 16 in relation to their neonatal condition. In each group the absolute figures are given and these are then expressed in percentages. Those groups of infants who were originally dyspnoeic or affected by cyanotic attacks contain a relatively greater number of abnormal babies than the group whose neonatal course was uncomplicated.

Growth. Reports concerning the physical progress made by children of diabetic women have, until recently, emanated mainly from Boston. From the large numbers available to White, Koshy and Duckers (1953) 105 children were selected because they lived near the Joslin Clinic. The children were

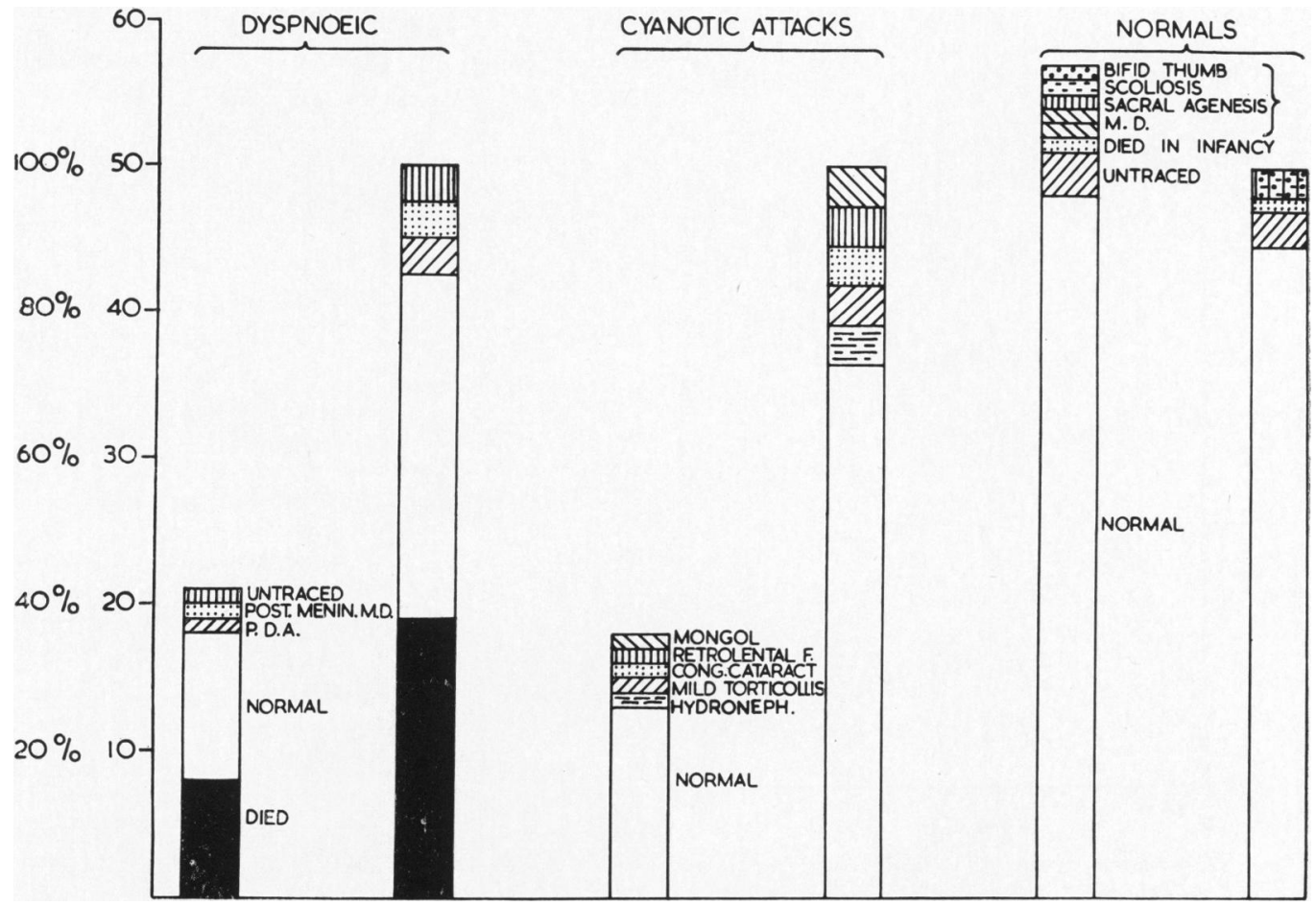

Fig. 16.-Neonatal condition and later development. 
stated to be commonly above average height and weight, but the information given does not constitute proof that, as a group, they were necessarily abnormal.

Selecting their cases only by response to their invitation to them to submit to examination, Fredrikson et al. (1957) examined 123 surviving children from a much larger group born to both pre-diabetic and diabetic women. When the heights and weights were compared with Swedish normal values, the children who were born before the onset of maternal diabetes were found to be below average and the difference was claimed to be significant statistically. Those born after the onset of the disease were on average slightly taller than normal but the difference was small and statistically not significant. The weights of the children did not differ from the normal.
The surviving Edinburgh cases were re-examined in 1955 and again in 1957. Almost all were examined and measured personally. The very few exceptions were mostly overseas where they were examined by doctors employing the same techniques. The same measuring rod and beam balance were used for all except the overseas children. The standing height was measured with the child stripped and erect against a wall, and the naked weight was measured by an Avery beam balance of checked accuracy. In the case of children of 18 months or less the total length, rather than the standing height, was measured with the apparatus devised by Thomson (1956). The heights at one or both examinations are shown in Fig. 17. The heights of the group of matched controls (see Congenital Malformations) are also recorded. The unbroken line represents the mean height derived from cross-sectional data

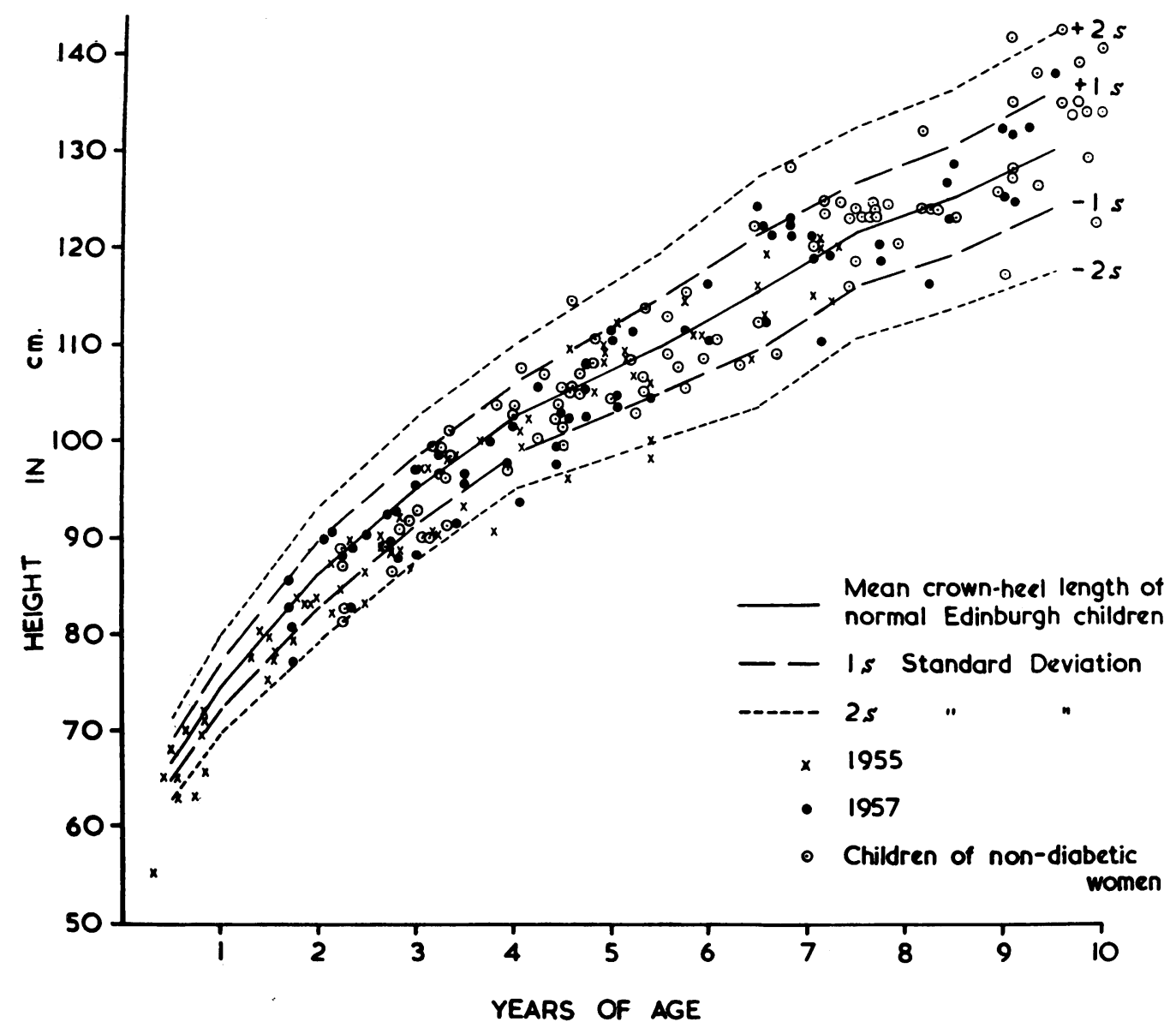

Fig. 17.-The later heights of children born to diabetic and non- diabetic women. (Compared with the crown-heel length of normal Edinburgh children.) 


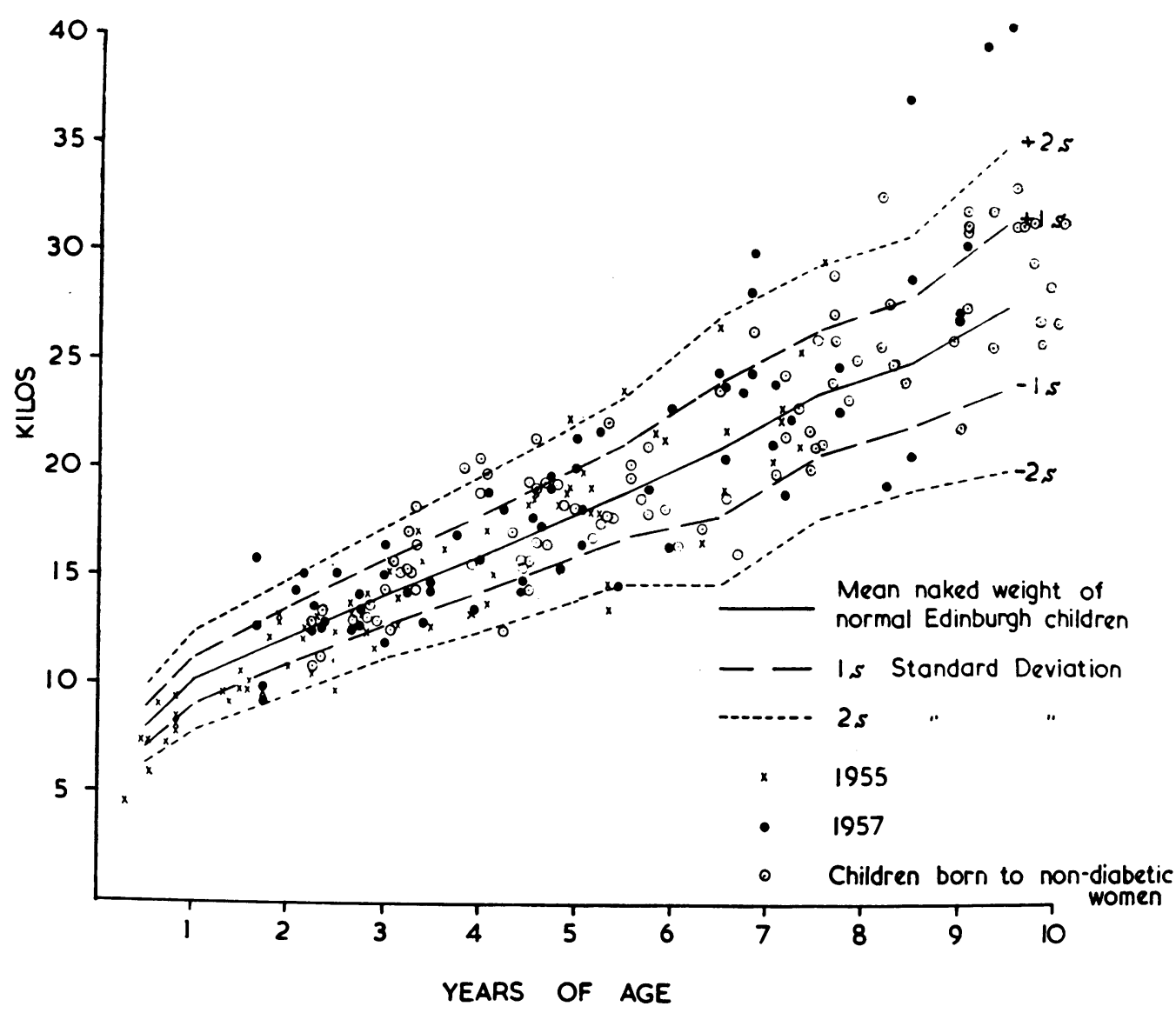

FIG. 18.-The later naked weights of children born to diabetic and non-diabetic women. (Compared with the naked weights of normal Edinburgh children.)

for Edinburgh pre-school (Thomson, 1956) and school-age children (Provis and Ellis, 1955) of the present decade. The broken lines represent \pm 1 and \pm 2 standard deviations (S.D.) about the mean at each year. No abnormality of linear growth is so far detectable in the diabetic group.

The weights of children in the diabetic group at one or two examinations and those of the children in the control group are shown in Fig. 18. The normal mean and standard deviations for weight from the same Edinburgh studies are recorded. A few children lie above or below the \pm 2 S.D. lines, but four lie above +3 S.D. and three of these are in the ninth or tenth years of age.

Birth Weight and Later Height. The birth weight, which is subject to the limitations previously mentioned, is recorded against the later height and age in Fig. 19. Those children who weighed $4 \mathrm{~kg}$. or more and who were weighed on two later occasions are linked on the graph. The only child to gain weight steeply in the interval between examinations is indicated. He was of lower birth weight. There is no indication that those babies who are very big at birth 'grow away' from the others with the passage of years. They do tend to remain among the taller children, but there are exceptions and some of the lighter babies at birth are later found among the taller children.

Birth Weight and Later Weight. The birth weight is recorded against the later weight and age in Fig. 20. There is no indication that those babies who exceeded $4 \mathrm{~kg}$. at birth are excessively heavy later. There is perhaps instead a tendency for them to be of average weight by the age of 7 years. Of 


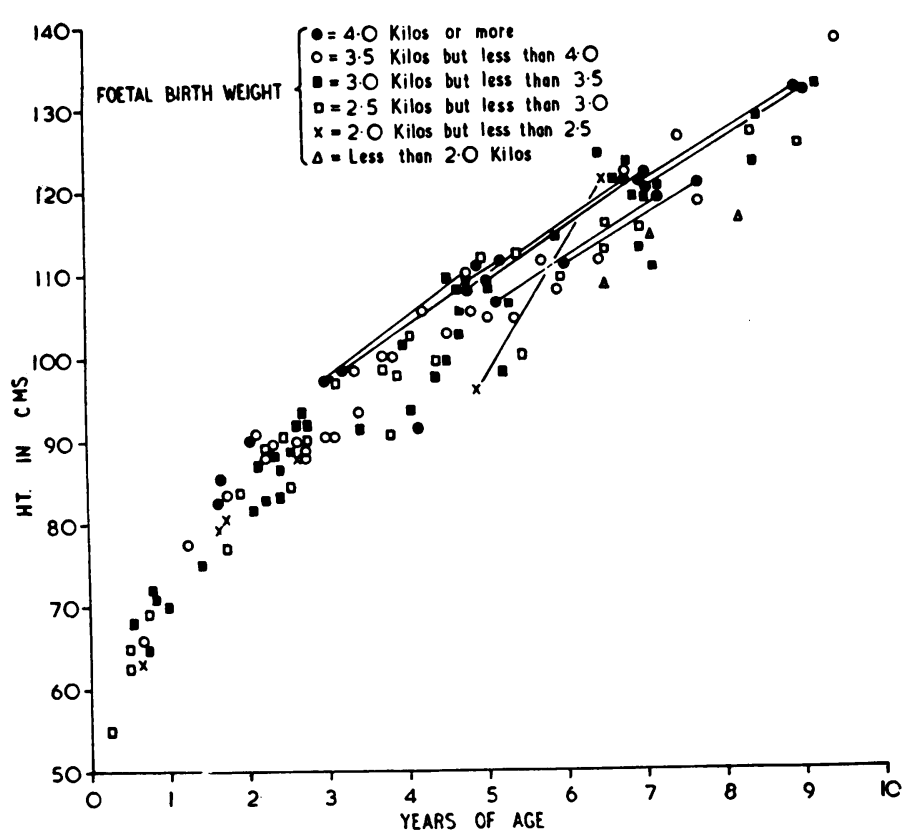

FIG. 19.-The relationship between birthweight and later height. of diabetic parents would probably develop the disease and that the presence of diabetes in the families of both parents increases the risk of diabetes in the child even if the parents themselves are unaffected. The development of the disease in one in four children born to diabetic women was forecast by Reis et al. (1952). A study of 1,241 diabetic propositi (Harris, 1950-51) showed that of the 1,418 children born to them only 10 became diabetic, and he estimated that about $1.4 \%$ of children of a diabetic parent may be expected to develop the disease by the age of 40 years.

By means of oral glucose tolerance tests Ditzel, White and Duckers (1954) found that of 75 children of diabetic mothers seven were already diabetic and a further 13 were 'borderline' diabetics. This incidence is surprising even when taking into consideration the fact that two thirds of the diabetics and

the three children whose weight exceeded +3 S.D. less than half the suspects were over the age of 10 of the mean in the ninth and tenth years, none years. The chances of the offspring of a single exceeded $4 \mathrm{~kg}$. at birth and two weighed $3.5 \mathrm{~kg}$. or diabetic parent eventually developing diabetes were less. These three had shown a sharp increase in weight in two years but other children of comparable birth weight were of average or low weight later.

Development of Diabetes Mellitus. The previous sections indicate that if the infants of diabetic women survive the newborn period then they are likely to be as healthy and to grow as normally as the children of nondiabetic women at least until the age of 10 years. But the possibility exists that a population is being salvaged which will live to develop and to propagate diabetes mellitus.

There is little doubt that the predisposition to diabetes mellitus is often inherited (Pincus and White, 1933; Harris, 1950-51; Bartels, 1953; Steinberg, 1955). The child of the diabetic woman was not considered by Skipper (1933) to be especially liable to the disease, but Peel and Oakley (1950) believed that the child

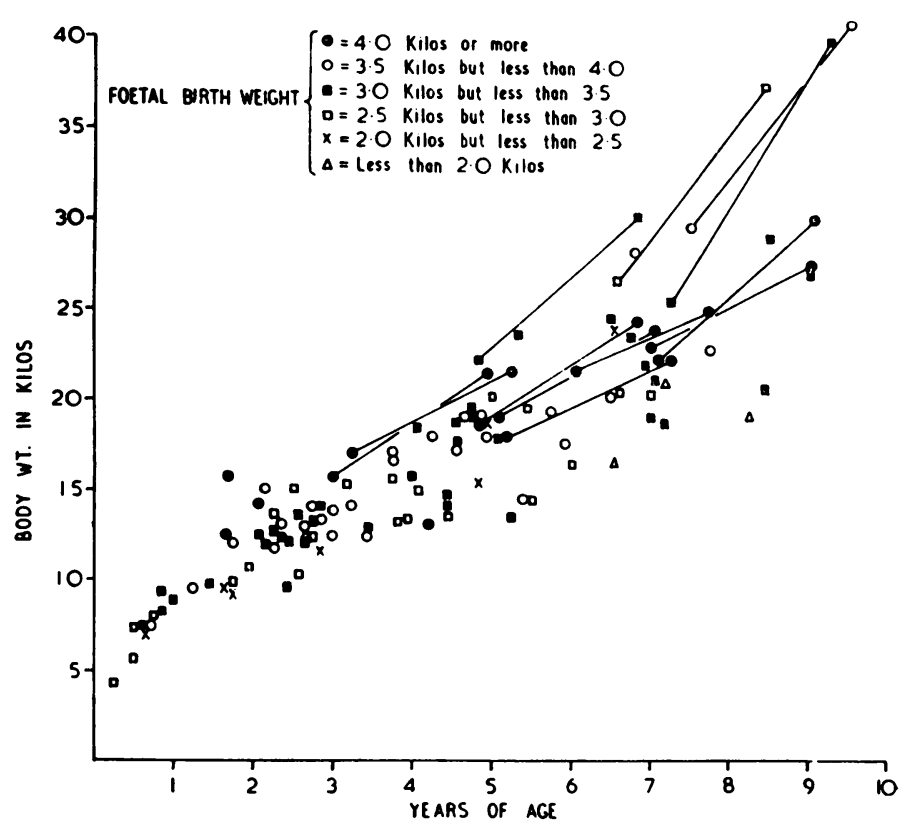

Fig. 20.-The relationship between birthweight and later weight. 
later estimated to be $22 \%$ for their whole life span (White, 1957). In contrast, of the 123 children studied by Fredrikson et al. (1957) only one was found to be diabetic. The children of the present series have not been subjected to glucose tolerance tests, but none has developed diabetes so far and none shows glycosuria after oral loading with glucose. None of them has developed the precocious growth described by Ditzel et al. (1954) as being associated closely with reduced glucose tolerance and vascular changes. The numbers of course at each age are relatively small, but the total is no smaller than the Boston group and it has the virtue of being unselected. Selection of cases from the area conveniently placed to a famous diabetic clinic could introduce considerable bias into the results. It may favour particular social or racial groups or diabetic parents who live there so that their own surveillance might be made easier.

The prediction of diabetes mellitus in the present series by using the steroid-glucose tolerance test (Fajans and Conn, 1954) has not been attempted so far. The obese children in a small series investigated in this way by Komrower (1957) showed no evidence of being pre-diabetic, and West (1957), using prednisolone, found that positive results were less commonly found in younger than in older subjects, and he suggested that the test was of only limited ability in the prediction of eventual diabetes mellitus.

The chances of inheritance when both parents are diabetic may be high, but the risk when only the mother is diabetic is still uncertain. Time will provide the answer more effectively and with less likelihood of making mothers anxious and children unhappy than the purely mechanical use of laboratory prediction methods with the associated need for explanation and hospital admission.

\section{Summary}

Although the development of insulin improved the fertility of diabetic women it created the problem of the diabetic pregnancy in which the viable foetal loss rate is still high.

The latter may be reduced by combined management of the pregnancy by a small team consisting of obstetrician, physician and paediatrician.

Even then, however, the foetus may still die in utero in the last month or less commonly, in the first few days of extra-uterine life.

The majority of babies are both heavy and long for their gestational age.

Many babies suffer from prolonged dyspnoea or from cyanotic attacks during the first few days of life. Of these, those with dyspnoea have the poorest prognosis.

The mortality and morbidity are highest among the smaller babies at any gestational age.

No clear relationship exists between maternal build and foetal birth weight but the latter varies with maturity. The birth weight may be remarkably consistent in families, however, and some women almost consistently give birth to giant offspring, among whom there is no increase in the mortality rate.

Conversely the risk of foetal death is greater in some women than in others, and their babies are not necessarily large. Gigantism and foetal death do not apparently result from the same maternal disorder.

The most frequent findings at autopsy are pulmonary hyaline membrane and hyperplasia of the pancreatic islets.

Circumstantial evidence exists of foetal hyperinsulinism.

Hyperinsulinism may result in utero from stimulation by maternal P.G.H. or corticotrophin.

There is evidence that the health of the foetus is influenced adversely by functional degeneration of the placenta. This may result from poor diabetic control, from acceleration of the placental life-span or from the influence of adrenal steroids. Of these only the first can be influenced at present.

The treatment of the foetus is briefly outlined.

Breast feeding is infrequently successful, but to any possible maternal endocrine cause for this may be added many extrinsic factors which interfere with the feeding situation.

The incidence of important congenital malformations may be no higher among children born to diabetic women than in normal children.

Those infants whose neonatal course is uneventful are less likely than others to show evidence of malformation later.

The heights and weights of children of various ages up to 10 years in this series differ very little from those for children born to non-diabetic mothers in the same city.

The size of the baby at birth bears no consistent relationship to its later growth.

None of the 88 babies who survived the newborn period has so far developed clinical diabetes mellitus. None shows glycosuria after oral glucose loads. No steroid-glucose tolerance tests have been undertaken.

The newborn child of the diabetic woman has been influenced in its intra-uterine development not only by genetic constitution but by the diabetic environment. His excessive growth may very well result from maternal P.G.H., but another factor, possibly 
adrenal steroid, is responsible for placental degeneration and foetal distress or death.

I wish to thank Dr. G. Douglas Matthew and Professor R. W. B. Ellis for their original invitation to take paediatric responsibility for the infants born to diabetic women, and for their advice on various matters during the 10 years since. I am grateful to Mr. Clifford Shepley and his staff for the illustrations, to Mr. G. R. Pendrill and Miss B. Newton, Librarian and Assistant Librarian respectively of the Royal College of Physicians of Edinburgh, for help with the literature and for translations, to Miss A. Brown and Miss D. Trench for help with various parts of the work, and to Miss E. Meikeljohn for most efficient secretarial assistance. Finally, I wish to thank the Committee of the Honyman Gillespie Trust for their invitation to deliver this lecture.

\section{REFERENCES}

Adams, T. W. (1955). Obstet. Gynec., 5, 160.

Avery, M. E., Oppenheimer, E. H. and Gordon, H. H. (1957). New Engl. J. Med., 256, 1134.

Baar, H. S. (1956). Discussion following Paper 106. VIIIth International Congress of Paediatrics, Copenhagen.

Babbott, D., Rubin, A. and Ginsburg, S. J. (1958). Diabetes, 7, 33 Barcroft, J. (1947). In Child Health and Development by R. W. B. Ellis. Churchill, London.

Barns, H. H. F. and Morgans, M. E. (1949). Brit. med. J., 1, 51.

- (1952). Ibid., 1, 1058.

Bartels, E. D. (1953). In Clinical Genetics, ed. by A. Sorsby. Butterworth, London.

Becker, B. (1952). Ann. intern. Med., 37, 273.

-, Maengwyn-Davies, G. D., Rosen, D., Friedenwald, J. S. and Winter, F. C. (1954). Diabetes, 3, 175 .

Beek, C. van (1952). Report on the 1st International Congress of the International Diabetes Federation, Leyden, Netherlands. 1952 , p. 28 (abstract).

Bennewitz, H. G. (1828). Edinb. med. surg. J., 30, 217.

Berglund, G. and Zetterström, R. (1954). Acta paediat. (Uppsala), $43,368$.

Björklund, S. I. (1953). Ibid., 42, 526.

Born, G. V. R., Dawes, G. S., Mott, J. C. and Widdicombe, J. G. (1954). Cold Spr. Harb. Symp. quant. Biol., 19, 102.

Boutourline-Young, H. J. and Smith, C. A. (1950). Amer. J. Dis. Child., 80, 753 .

Cardell, B. S. (1953). J. Obstet. Gynaec. Brit. Emp., 60, 834.

Clayton, S. (1956). Scot. med. J., 1, 138.

Cope C. L., Boysen, X. and McCrae, S. (1951). Brit. med. J., $2,762$.

Craig, W. S. and Buchanan, M. F. G. (1958). Arch. Dis. Childh., 33, 505.

Dawes, G. S., Mott, J. C., Widdicombe, J. G. and Wyatt, D. G. (1953). J. Physiol. (L̈ond.), 121, 141.

Ditzel, J., White, P. and Duckers, J. (1954). Diabetes, 3, 99.

- and Moinat, P. (1957). Ibid., 6, 307.

Duncan, J. M. (1883). Trans. obstet. Soc. Lond., 1882, 24, 256.

Duncan, L. J. P., MacFarlane, A. and Robson, J.' S. (1958). Lancet, 1, 822 .

Dunlop, D. M. (1954). Brit. med. J., 2, 383.

Ellis, R. W. B. (1951). Arch. Dis. Childh., 26, 411

Eshner, A. A. (1907). Amer. J. med. Sci., 134, 375.

Fajans, S. S. and Conn, J. W. (1954). Diabetes, 3, 296.

Farquhar, J. W. (1954). Arch. Dis. Childh., 29, 519.

- (1955). Ibid., 30, 133 . 1 .

(1956a). Ibid., 31, 203.

and Sklaroff, S. (1958). Ibid., 33, 323.

- and Smith, H. (1958). Ibid., 33, 142 .

Fredrikson, H., Hagbard, L., Olow, I. and Reinand, R. (1957). Nord. Med., 57, 669 .

Futcher, P. H and Long, N. W. (1954). Bull. Johns Hopk. Hosp., 94, 128.

Gairdner, D., Marks, J., Roscoe, J. D. and Brettell, R. O. (1958). Arch. Dis. Child., 33, 489.

Gellis, S. S., White, P. and Pfeffer, W. (1949). New Engl. J. Med., $240,533$.

Gilbert, J.'A. L. (1949). Brit. med. J., 1, 702.

Grayzel, H. G., Warshall, H. B., Elkan, B. and Sternberg, A. (1957). Diabetes, 6, 480

Hagbard, L. (1956). Acta obstet. gynec. scand., 35, Suppl. 1 .

Hall, R. E. and Tillman, A. J. B. (1951). Amer. J. Obstet. Gynec., 61, 1107 .
Harris, H. (1950-51). Ann. Eugen. (Lond.), 15, 95.

Herman, G. E. (1902) Edinb. med. J., n.s. 11, 119.

Hoet, J. P. (1954). Diabetes, 3, 1 .

Hsia, D. Y-Y., Peterson, H. G. and Gellis, S. S. (1957). Pediatrics, 20,234 .

Ikkos, D., Luft, R. and Gemzell, C. A. (1958). Lancet, 1, 720.

Klein, R., Papadatos, C., Fortunato, J. and Byers, C. (1955). J. clin. Endocr., 15, 215.'

Weigand, F. A., Iunes, M. and Greenman, L. (1956). Pediatrics, 17, 214 .

Komrower, G. (1957). Personal communication.

Lawrence, R. D. (1950). Brit. med. J., 2, 107.

Luft, R., Ikkos, D., Gemzell, C. A. and Olivecrona, H. (1958). Lancet, 1, 721.

McCance, R. A. (1955). Personal communication.

Mcllroy, L., Hili, G. and Pillman-Williams, E. C. (1931). Postgrad. med.'J., 6, 159.

Mackay, D. G.' (1952). Reported by P. White in Treatment of Diabetes Mellitus by E. P. Joslin et al., 9 th ed.

MacKay, R. B. (1955). M.D. Thesis. University of Edinburgh.

Mack (1957). J. Obstet. Gynaec. Brit. Emp., 64, 185

Maengwyn-Davies, G. D., Lerman, S., Pogell, B. M., Stone, H. H. and Friedenwald, J. S. (1956). Bull. Johns Hopk. Hosp., 99, 16.

- Marrian, G. F. (1951). J. Endocr., 7, proc. 1xix.

Medical Research Council (1955). Lancet, 2, 833.

Merkler, D. (1929). Med. Klin., 25, 1468.

Miller, H. C., Hurwitz, D. and Kuder, K. (1944). J. Amer. med. Ass., 124, 271.

Oppé, T. E., Hsia, D. Y-Y. and Gellis, S. S. (1957). Lancet, 1, 353.

Patterson, M. and Burnstein, N. (1949). Arch. intern. Med., 83, 390.

Peckham, C. H. (1931). Bull. Johns Hopk. Hosp., 49, 184.

Pedersen, J. (1952). Diabetes and Pregnancy. Danish Science Press, Copenhagen.

(1954). Acta endocr. (Kbh.), 16, 330.

- (1954). Acta endocr. (Kbh.), 16, 330.. 1,607

Pedowitz, P. and Shlevin, E. L. (1955). Amer. J. Obstet. Gynec., 69, 395 .

Peel, J. H. (1951). Practitioner, 166, 143.

(1955). Brit. med. J., 2, 870.

and Oakley, W. (1950). Trans. 12th Brit. Congr. Obstet. Gynaec. London.

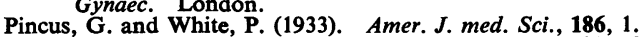

Pincus, G. and White, P. (1933). Amer. J. med. Sci., 186, 1.
Provis, H. S. and Ellis, R. W. B. (1955). Arch. Dis. Childh., 30, 328.

Prystowsky, H. (1957). Bull. Johns Hopk. Hosp., 101, 48.

Read, C. H. (1951). Trans. int. and 4th Amer. Congr. Obstet, Gynec. Amer. J. Obstet. Gynec., 61A, 392.

Reis, R. A., DeCosta, E. J. and Allweiss, M.D. (1950). Ibid., 60, 1023.'

Richardson, G. O., Snaith, L. and Sibley, J. C. (1955). J. Obstet. Gynaec. Brit. Emp., 62, 262.

Rifkin, H., Solomon, S. and Lieberman, S. (1958). Diabetes, 7, 9.

Rolland, C. (1954). Edinb. med. J., 61, 257.

Sheumack, D. R. (1949). Med. J. Aust., 2, 553.

Sinden, J. A. and Longwell, B. B. (1949). Proc. Soc. exp. Biol. (N.Y.) $70,607$.

Skipper, E. (1933). Quart. J. Med., 26 (n.s. 2), 353.

Steinberg, A. G. (1955). Eugen. Quart., 2, 26.

Stevenson, A. E. M. (1956). Brit. med. J., 2, 1514.

Talbot, N. B., Sobei, E. H., McArthur, J.'W. and Crawford, J. D. (1952). Functional Endocrinology. From Birth through Adolescence. Harvard University Press, Cambridge, Mass.

Tejning, S. (1947). Acta med. scand., suppl. 198.

Thomson, J. (1956). Quoted by R. W. B. Ellis in Child Health and Development, 2nd ed. (1956). Churchill, London.

Tompsett, S. L. and Smith, D. C. (1954). J. clin. Endocr., 14, 922.

Turnbull, E. P. N. and Baird, D. (1957). Brit. med. J., 2, 1.

Tveterås, E. and Rudström, P. (1956). Acta paediat. (Uppsala), $45,545$.

Van Breemen, V. L., Neustein, H. B. and Bruns, P. D. (1957). Amer. J. Path., 33, 769 .

Walker, J. (1954). J. Obstet. Gynaec. Brit. Emp., 61, 162.

and Turnbull, E. P. N. (1953). Lancet, 2, 312.

West, K. M. (1957). Diabetes, 6, 168.
White, P. (1949). Amer. J. Med., 7, 609.

1952). In Treatment of Diabetes Mellitus by E. P. Joslin. 9th ed. Diabetes, 6, 523.
(1957).

-, Gillespie, L. and Sexton, L. (1956). Amer. J. Obstet. Gynec., 71, 57.

Koshy, P. and Duckers, J. (1953). Med. Clin. N. Amer., 37,1481 .

Wilder, R. M. and Parsons, E. (1928). Colo. Med., 25, 372.

Wilkins, L (1957). The Diagnosis and Treatment of Endocrine Disorders in Childhood and Adolescence, 2nd ed. Thomas, Springfield, Illinois.

Williams, R. H. (1955). Textbook of Endocrinology, 2nd ed. Saunders, Philadelphia. 